\title{
Measurement report: Regional characteristics of seasonal and long-term variations in greenhouse gases at Nainital, India, and Comilla, Bangladesh
}

\author{
Shohei Nomura ${ }^{1}$, Manish Naja ${ }^{2}$, M. Kawser Ahmed ${ }^{3}$, Hitoshi Mukai ${ }^{1}$, Yukio Terao ${ }^{1}$, Toshinobu Machida ${ }^{1}$, \\ Motoki Sasakawa ${ }^{1}$, and Prabir K. Patra ${ }^{4}$ \\ ${ }^{1}$ Center for Global Environmental Research, National Institute for Environmental Studies, 16-2 Onogawa, \\ Tsukuba, Ibaraki, 305-8506, Japan \\ ${ }^{2}$ Aryabhatta Research Institute of Observational Sciences, Manora Peak, Nainital Uttarakhand 263129, India \\ ${ }^{3}$ Department of Oceanography, Faculty of Earth \& Environmental Sciences, University of Dhaka, Dhaka-1000, Bangladesh \\ ${ }^{4}$ Research Institute for Global Change, JAMSTEC, 3173-25 Showa-machi, Yokohama, 236-0001, Japan
}

Correspondence: Shohei Nomura (nomura.shohei@nies.go.jp)

Received: 13 April 2021 - Discussion started: 21 May 2021

Revised: 11 September 2021 - Accepted: 22 September 2021 - Published: 10 November 2021

\begin{abstract}
Emissions of greenhouse gases (GHGs) from the Indian subcontinent have increased during the last 20 years along with rapid economic growth; however, there remains a paucity of GHG measurements for policy-relevant research. In northern India and Bangladesh, agricultural activities are considered to play an important role in GHG concentrations in the atmosphere. We performed weekly air sampling at Nainital (NTL) in northern India and Comilla (CLA) in Bangladesh from 2006 and 2012, respectively. Air samples were analyzed for dry-air gas mole fractions of $\mathrm{CO}_{2}, \mathrm{CH}_{4}$, $\mathrm{CO}, \mathrm{H}_{2}, \mathrm{~N}_{2} \mathrm{O}$, and $\mathrm{SF}_{6}$ and carbon and oxygen isotopic ratios of $\mathrm{CO}_{2}\left(\delta^{13} \mathrm{C}-\mathrm{CO}_{2}\right.$ and $\left.\delta^{18} \mathrm{O}-\mathrm{CO}_{2}\right)$. Regional characteristics of these components over the Indo-Gangetic Plain are discussed compared to data from other Indian sites and Mauna Loa, Hawaii (MLO), which is representative of marine background air.

We found that the $\mathrm{CO}_{2}$ mole fraction at CLA had two seasonal minima in February-March and September, corresponding to crop cultivation activities that depend on regional climatic conditions. Although NTL had only one clear minimum in September, the carbon isotopic signature suggested that photosynthetic $\mathrm{CO}_{2}$ absorption by crops cultivated in each season contributes differently to lower $\mathrm{CO}_{2}$ mole fractions at both sites. The $\mathrm{CH}_{4}$ mole fraction of NTL and CLA in August-October showed high values (i.e., sometimes over $4000 \mathrm{ppb}$ at CLA), mainly due to the influence
\end{abstract}

of $\mathrm{CH}_{4}$ emissions from the paddy fields. High $\mathrm{CH}_{4}$ mole fractions sustained over months at CLA were a characteristic feature on the Indo-Gangetic Plain, which were affected by both the local emission and air mass transport. The $\mathrm{CO}$ mole fractions at NTL were also high and showed peaks in May and October, while CLA had much higher peaks in OctoberMarch due to the influence of human activities such as emissions from biomass burning and brick production. The $\mathrm{N}_{2} \mathrm{O}$ mole fractions at NTL and CLA increased in June-August and November-February, which coincided with the application of nitrogen fertilizer and the burning of biomass such as the harvest residues and dung for domestic cooking. Based on $\mathrm{H}_{2}$ seasonal variation at both sites, it appeared that the emissions in this region were related to biomass burning in addition to production from the reaction of $\mathrm{OH}$ and $\mathrm{CH}_{4}$. The $\mathrm{SF}_{6}$ mole fraction was similar to that at MLO, suggesting that there were few anthropogenic $\mathrm{SF}_{6}$ emission sources in the district.

The variability of the $\mathrm{CO}_{2}$ growth rate at NTL was different from the variability in the $\mathrm{CO}_{2}$ growth rate at MLO, which is more closely linked to the El Niño-Southern Oscillation (ENSO). In addition, the growth rates of the $\mathrm{CH}_{4}$ and $\mathrm{SF}_{6}$ mole fractions at NTL showed an anticorrelation with those at MLO, indicating that the frequency of southerly air masses strongly influenced these mole fractions. These findings showed that rather large regional cli- 
matic conditions considerably controlled interannual variations in GHGs, $\delta^{13} \mathrm{C}-\mathrm{CO}_{2}$, and $\delta^{18} \mathrm{O}-\mathrm{CO}_{2}$ through changes in precipitation and air mass.

\section{Introduction}

The mole fraction of many greenhouse gases (GHGs) in the atmosphere, including $\mathrm{CO}_{2}, \mathrm{CH}_{4}$, and $\mathrm{N}_{2} \mathrm{O}$, has been increasing worldwide in recent years. As for $\mathrm{CO}_{2}$, rapid increases in $\mathrm{CO}_{2}$ emissions from developing countries contribute strongly to acceleration of the growth rate of its mole fraction (Friedlingstein et al., 2019). For instance, the anthropogenic $\mathrm{CO}_{2}$ emission of India increased in 2017: it reached $2.45 \mathrm{GtCO}_{2} \mathrm{yr}^{-1}$, which was the third highest in the world (Muntean et al., 2018). Therefore, the South Asian region must be important for evaluating GHGs in the future. Patra et al. (2013) calculated the $\mathrm{CO}_{2}$ flux in South Asia using the top-down and bottom-up methods and reported that $\mathrm{CO}_{2}$ fluxes top down and bottom up were $-104 \pm 150$ and $-191 \pm 193 \mathrm{TgCyr}^{-1}$. In other words, $\mathrm{CO}_{2}$ was absorbed in South Asia; however, the error of $\mathrm{CO}_{2}$ flux was very large because there are only a few measured GHG mole fractions in the South Asian region.

The first systematic monitoring for GHG mole fractions and carbon isotopic ratios in the South Asian region was performed by Bhattacharya et al. (2009). They carried out monitoring at the Cape Rama, India, station (CRI) $\left(15.1^{\circ} \mathrm{N}\right.$, $73.9^{\circ} \mathrm{E} ; 60 \mathrm{~m}$ a.s.1.) on the western coast of India from 1993 and found that (1) the $\mathrm{CH}_{4}$ and $\mathrm{CO}$ mole fractions increased in October-March, when the air mass came from the northeast (inland) and decreased in June-August, when the air mass came from the southwest (ocean), (2) the $\mathrm{CO}_{2}, \mathrm{CH}_{4}$, $\mathrm{CO}, \mathrm{H}_{2}$, and $\mathrm{N}_{2} \mathrm{O}$ mole fractions in June-August were generally at the same levels at the background sites at the observatory in the Seychelles and Hawaii, and that (3) the seasonal cycle and phase in the $\mathrm{CH}_{4}$ and $\mathrm{CO}$ mole fractions were quite similar and their correlation coefficient was high, generally because they originated from anthropogenic emissions in India. Therefore, it became clear that GHG mole fractions are greatly changed by the seasonal wind and that the Indian subcontinent has strong $\mathrm{CH}_{4}$ and $\mathrm{CO}$ emissions.

In recent decades, a few more research groups have commenced flask sampling or continuous GHG measurements in India. Sharma et al. (2013) measured atmospheric $\mathrm{CO}_{2}$ mole fractions at Dehradun in northern India in 2009 and detected that the $\mathrm{CO}_{2}$ mole fraction decreased twice a year (March and September) due to vegetation activity. Ganesan et al. (2013) measured the $\mathrm{CH}_{4}, \mathrm{~N}_{2} \mathrm{O}$, and $\mathrm{SF}_{6}$ mole fractions in December 2011 to February 2013 at Darjeeling in northeastern India and found that (1) $\mathrm{CH}_{4}$ mole fractions had a positive correlation with the $\mathrm{N}_{2} \mathrm{O}$ mole fraction and that those mole fractions increased due to emissions from anthropogenic activities when air masses came from the Indo-
Gangetic Plain and that (2) $\mathrm{SF}_{6}$ emissions in the region showed a weak signal. Chandra et al. (2016) measured the $\mathrm{CO}_{2}$ and $\mathrm{CO}$ mole fractions at Ahmedabad in western India and detected a decrease in the mole fraction when the air mass comes from the southwest (ocean) and an increase in the mole fraction when the air mass comes from the northeast (inland). Tiwari et al. (2014) analyzed the spatial variability of atmospheric $\mathrm{CO}_{2}$ mole fractions using models over the Indian subcontinent and began the flask sampling at Sinhagad in the western Ghats. They showed that (1) the seasonal variation of the $\mathrm{CO}_{2}$ mole fraction in southern India differed with the variation on the Indo-Gangetic Plain in northern India due to the differences in air mass transportation and anthropogenic activity and that (2) the $\mathrm{CO}_{2}$ mole fraction in JulyOctober at Sinhagad was lower than the mole fraction of CRI on the western coast of India because of the influence of photosynthesis by the regional forest ecosystem.

Sreenivas et al. (2016) measured the mole fractions of $\mathrm{CO}_{2}$ and $\mathrm{CH}_{4}$ at Shadnagar in central India and reported that the $\mathrm{CO}_{2}$ and $\mathrm{CH}_{4}$ mole fractions were strongly positively correlated with anthropogenic sources. Lin et al. (2015) commenced the most ambitious flask sampling network, with sites at Pondicherry (PON) on the southeastern coast of India, Port Blair (PBL) in the Andamans, and Hanle (HLE) in the northwestern Himalaya. They reported that (1) the mole fractions of $\mathrm{CH}_{4}, \mathrm{CO}$, and $\mathrm{N}_{2} \mathrm{O}$ at PON and PBL were relatively high in comparison with those at HLE and that (2) seasonal variations in GHGs at PON and PBL were quite different from the variation at HLE because the former two sites were exposed to the influence of air masses originating from areas of anthropogenic activities. In addition to these studies at ground sites, recently aircraft-base observations over the Indo-Gangetic Plain such as CONTRAIL have also been carried out actively, evaluating seasonal variation of the $\mathrm{CO}_{2}$ mole fraction (Umezawa et al., 2016).

Thus, the GHG observation program in the Indian region is expanding gradually; however, the characterization of GHG behavior in the northern Indian subcontinent and its long-term trends are not well understood. In this paper, we present the longer GHG data than previous studies on the Indo-Gangetic Plain, including Bangladesh, which is a blank area for GHG observation, and clarify the characteristics of GHGs in the Indian subcontinent by analyzing the periodicity of GHG growth rates and comparing them with regional climatic conditions. We, therefore, analyzed a 14-year record of various GHG mole fractions and isotopic ratios of $\mathrm{CO}_{2}$ $\left(\delta^{13} \mathrm{C}-\mathrm{CO}_{2}\right.$ and $\left.\delta^{18} \mathrm{O}-\mathrm{CO}_{2}\right)$ at Nainital, India, on a mountain site near the Himalayan mountain range, which can be considered a background site representing northern Indian air and which is partly influenced by anthropogenic activities from the Indo-Gangetic Plain. We also show a similar 8-year GHG record at Comilla, Bangladesh, located on the eastern edge of the Indo-Gangetic Plain, where agricultural activities are believed to be the main factors in GHG emissions. The levels and seasonal variabilities of the GHG mole frac- 
tion at these sites are discussed compared to those at other Indian sites reported previously, along with the local precipitation and $72 \mathrm{~h}$ back-trajectory to summarize the behavior of GHGs in this region. The relationships of mole fractions among GHGs are evaluated. We also describe isotopic characteristics of $\mathrm{CO}_{2}$ to consider contributions to absorption by $\mathrm{C}_{3}$ and $\mathrm{C}_{4}$ plants in each region. Furthermore, we analyze the relationships between the interannual variabilities in $\mathrm{GHG}$ growth rates and regional climatic condition such as the Indian Dipole Mode Index (DMI) and the El Niño-Southern Oscillation (ENSO) index.

\section{Methods}

\subsection{Location}

Figure 1 shows the locations of the Nainital station (NTL) and Comilla station (CLA), where we performed weekly sampling. The GHG observation sites in previous studies in the Indian subcontinent are also marked. NTL is located at the Aryabhatta Research Institute of Observational Sciences (ARIES) $\left(29.36^{\circ} \mathrm{N}, 79.46^{\circ} \mathrm{E} ; 1940 \mathrm{ma.s.1}\right.$.) on the top of Manora Peak at the foot of the Himalaya mountain range facing the Indo-Gangetic Plain. Also, NTL is located $3 \mathrm{~km}$ south of Nainital, and no local residential building is within $2 \mathrm{~km}$ from the station. The predominant wind direction at NTL is west-northwest during winter and east during summer (Naja et al., 2016), which means that the air of NTL is influenced mainly by the air mass passing through the Indo-Gangetic Plain rather than extremely influenced by local GHG emissions nearby.

CLA is located at the Comilla weather station of the Bangladesh Meteorological Department (BMD) $\left(23.43^{\circ} \mathrm{N}\right.$, $91.18^{\circ} \mathrm{E} ; 30 \mathrm{~m}$ a.s.1.) on the edge of a farming village with a flat landscape in central Bangladesh. The surrounding areas of CLA cover the paddy fields and a few farmhouses. The land use in the central Bangladesh region is almost exclusively agricultural land, with the structure of farms developing along the roads. Farmers in this region often burn the biomass (e.g. harvest residuals, firewood, and dung), and it was expected that $\mathrm{CO}_{2}, \mathrm{CH}_{4}, \mathrm{CO}, \mathrm{H}_{2}$, and $\mathrm{N}_{2} \mathrm{O}$ were emitted by the burning. Wind and precipitation are strongly influenced by monsoon, and sometimes cyclone hits this region. Wind speeds around the CLA are not very slow on average, e.g., 2-5 $\mathrm{m} \mathrm{s}^{-1}$. Therefore, we judged that this site can mainly capture the typical greenhouse gas emission and sink effects in central Bangladesh, which is located in the eastern IndoGangetic Plain, despite it partly capturing some effects from nearby emissions.

\subsection{Air sampling}

Flask samples were collected from September 2006 in NTL and from June 2012 in CLA. Inlets were mounted at $7 \mathrm{~m}$ above ground level (on the roof of the second floor of the sta- tion) in NTL and $8 \mathrm{~m}$ above ground level (on top of the $5 \mathrm{~m}$ tower on the roof of the one-storey weather station building) in CLA. The height of the inlet of NTL is 5-20 $\mathrm{m}$ higher than the height of the canopy close to the inlet. Air samples were collected once a week (usually on Wednesdays) at 14:00 LT into a 1.5 L Pyrex flask with two stopcocks sealed with Viton O-rings via a sampling line (Fig. 2a). The sampling line contained a diaphragm pump (MOA-P108-HB, GAST Co., Ltd.) and a freezer (VA-120, Taitec Co., Ltd.) for dehumidification by a glass trap. The sampling flow rate was approximately $2 \mathrm{Lmin}^{-1}$, and the sample was passed through $\mathrm{a}-30{ }^{\circ} \mathrm{C}$ cooler and pressurized to $0.25 \mathrm{MPa}$ after $10 \mathrm{~min}$ flushing through the sampling tube and flask. The sampled flasks were packed in a cardboard box and transported to the laboratory of the Center for Global Environmental Research (CGER), National Institute for Environmental Studies, Japan (NIES) (transportation period: 3-7 d), for analyses.

\subsection{Measurement methods}

An air sample was passed through a $-80^{\circ} \mathrm{C}$ cold trap for dehumidification and was delivered to each instrument with a flow rate of $40 \mathrm{~mL} \mathrm{~min}^{-1}$ (see the analysis line in Fig. 2b). A nondispersive infrared analyzer (NDIR; LI-COR, LI-6252) was used for $\mathrm{CO}_{2}$ analysis, a gas chromatograph equipped with a flame ionization detector (GC-FID; Agilent Technologies, HP-5890 or HP-7890) was used to analyze $\mathrm{CH}_{4}$, a gas chromatograph with a reduction gas detector (GC-RGD; Agilent Technologies, HP-5890+Trace Analytical RGD-2 or Peak Laboratories, Peak Performer $1 \mathrm{RCP}$ ) was used for $\mathrm{CO}$ and $\mathrm{H}_{2}$ analyses, and a gas chromatograph with an electron capture detector (GC-ECD) until 2011 and with a microelectron capture detector (GC-micro-ECD) from 2012 (Agilent Technologies, HP-6890) were used to analyze $\mathrm{N}_{2} \mathrm{O}$ and $\mathrm{SF}_{6}$.

The sample was injected into the analytical system three times per one flask, and the working standard gases were analyzed after every two flasks. Dry-air mole fractions were measured against each of their working standard gases, which were calibrated with NIES secondary standard gas series $\left(\mathrm{CO}_{2}\right.$-NIES09 scale, $\mathrm{CH}_{4}$-NIES94 scale, CO-NIES09 scale, $\mathrm{H}_{2}$-NIES96 scale, $\mathrm{N}_{2} \mathrm{O}$-NIES01 scale, and $\mathrm{SF}_{6}$-NIES01 scale). Comparison between those scales and the National Oceanic and Atmospheric Administration (NOAA) scale in the sixth Round Robin intercomparison (NOAA/ESRL, 2019a) showed -0.04 to $-0.09 \mathrm{ppm}$ for $\mathrm{CO}_{2}, 3.7$ to $4.1 \mathrm{ppb}$ for $\mathrm{CH}_{4}, 4.0$ to $4.4 \mathrm{ppb}$ for $\mathrm{CO},-0.61$ to $-0.69 \mathrm{ppb}$ for $\mathrm{N}_{2} \mathrm{O}$, and -0.03 to $-0.06 \mathrm{ppt}$ for $\mathrm{SF}_{6}$. We evaluated that the NIES scales were almost the same as NOAA scales except for $\mathrm{CH}_{4}$, which showed a bias that was beyond the measurement precision of our instrument.

The mole fractions of the respective working standard gases are 379.00, 403.01, 423.84, and 441.10 ppm for $\mathrm{CO}_{2}$, $1681.50,1852.12,1998.83$, and $2167.63 \mathrm{ppb}$ for $\mathrm{CH}_{4}, 59.84$, 164.57, 267.33, and $373.54 \mathrm{ppb}$ for $\mathrm{CO}, 401.40,502.98$, 


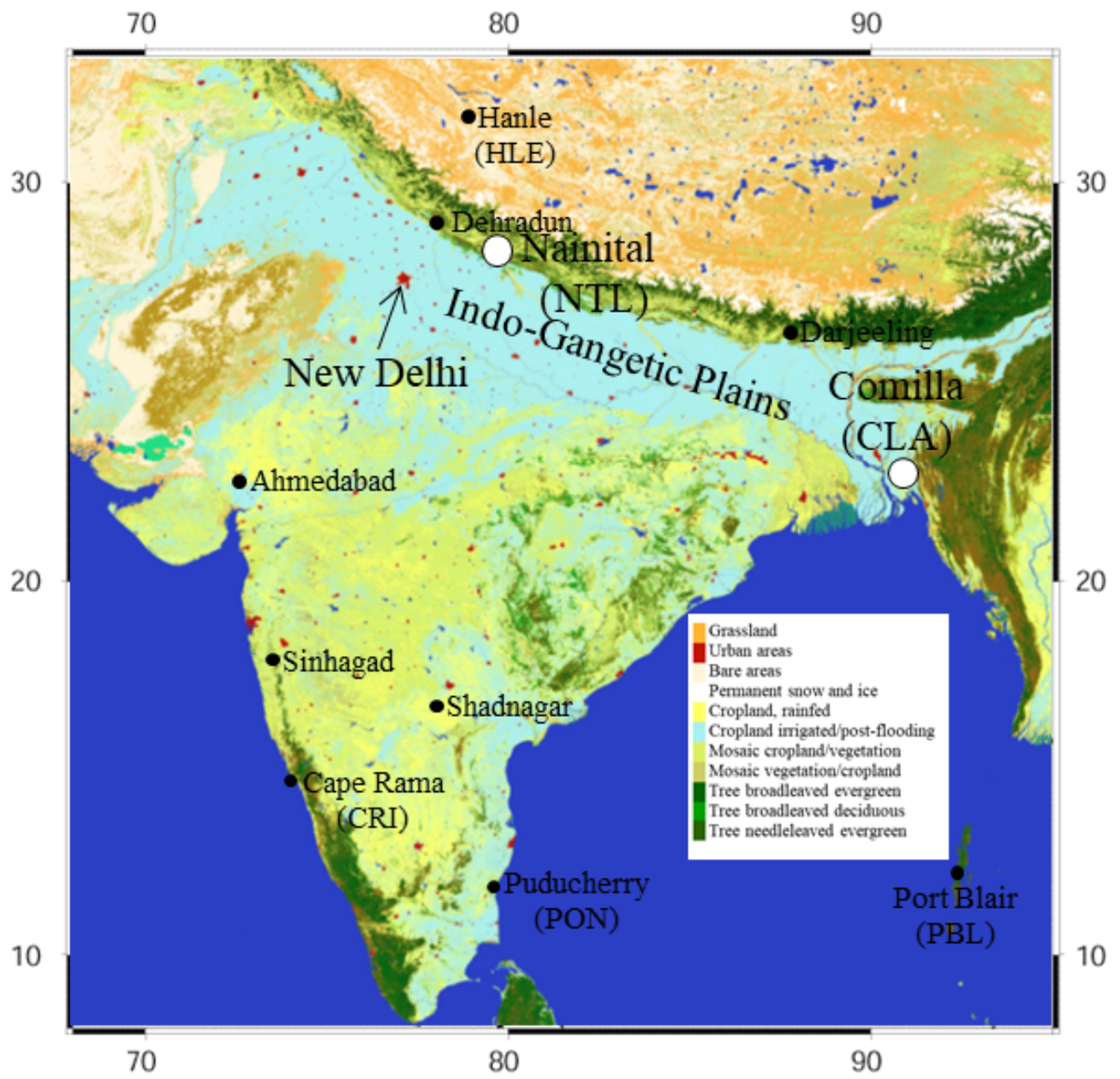

Figure 1. Locations of Nainital (NTL), India $\left(29.36^{\circ} \mathrm{N}, 79.46^{\circ} \mathrm{E} ; 1940 \mathrm{~m}\right.$ a.s.1.), Comilla (CLA), Bangladesh $\left(23.43^{\circ} \mathrm{N}, 91.18^{\circ} \mathrm{E}\right.$; $30 \mathrm{~m}$ a.s.1.), and other Indian sites for greenhouse gas (GHG) observation (Bhattacharya et al., 2009; Ganesan et al., 2013; Sharma et al., 2013; Tiwari et al., 2014; Lie et al., 2015; Sreenivas et al., 2016; Chandra et al., 2016) and showing land cover around the South Asia region (Arino et al., 2012).

610.49 , and $715.95 \mathrm{ppb}$ for $\mathrm{H}_{2}, 319.23,326.91,337.53$, and 345.54 ppb for $\mathrm{N}_{2} \mathrm{O}$, and 4.65, 9.77, 14.53, and 19.08 ppt for $\mathrm{SF}_{6}$. The analytical precision for the repetitive measurements is less than $0.03 \mathrm{ppm}$ for $\mathrm{CO}_{2}, 1.7 \mathrm{ppb}$ for $\mathrm{CH}_{4}, 0.3 \mathrm{ppb}$ for $\mathrm{CO}, 3.1 \mathrm{ppb}$ for $\mathrm{H}_{2}, 0.3 \mathrm{ppb}$ for $\mathrm{N}_{2} \mathrm{O}$, and $0.3 \mathrm{ppt}$ for $\mathrm{SF}_{6}$ (Machida et al., 2008).

After the mole fraction analysis, we used the remaining air inside the flask for analysis of $\delta^{13} \mathrm{C}-\mathrm{CO}_{2}$ and $\delta^{18} \mathrm{O}$ $\mathrm{CO}_{2}$. The air was introduced into two traps sequentially $\left(-100\right.$ and $\left.-197^{\circ} \mathrm{C}\right)$, which trapped $\mathrm{H}_{2} \mathrm{O}$ and $\mathrm{CO}_{2}$, respectively. Finally, $\mathrm{CO}_{2}$ was sealed in a glass tube. Air $\delta^{13} \mathrm{C}$ $\mathrm{CO}_{2}$ and $\delta^{18} \mathrm{O}-\mathrm{CO}_{2}$ were measured by MT-252 using the working standard $\mathrm{CO}_{2}$ gas which was prepared in our laboratory. The method for producing the working standard gas is similar to the method for producing the NIES Atmospheric Reference $\mathrm{CO}_{2}$ for Isotopic Studies (NARCIS), which is used for interlaboratory-scale comparison (Mukai, 2001). The working standard scales of $\delta^{13} \mathrm{C}-\mathrm{CO}_{2}$ and $\delta^{18} \mathrm{O}-$
$\mathrm{CO}_{2}$ are the same as those of NARCIS, which were measured by various institutions related to the World Meteorological Organization (WMO) (Mukai, 2003). The differences between NIES scales and INSTAAR (Institute of Arctic and Alpine Research) scales were $0.013 \%$ o $0.039 \%$ in the mean value range of $-8.683 \%$ o to $-8.759 \%$ ofor $\delta^{13} \mathrm{C}-\mathrm{CO}_{2}$ and $-0.017 \%$ o $-0.022 \%$ in the mean value range of $-1.956 \%$ o to $-9.299 \%$ of $\delta^{18} \mathrm{O}-\mathrm{CO}_{2}$ in the 6th Round Robin intercomparison (NOAA/ESRL, 2019a). The $\delta^{18} \mathrm{O}-\mathrm{CO}_{2}$ for atmospheric $\mathrm{CO}_{2}$ in this study is expressed against the value of $\mathrm{CO}_{2}$ evolved from VPDB calcite (i.e., VPDB-CO $\mathrm{CO}_{2}$ scale, IAEA, 1993; Brand et al., 2010). Although the Vienna Standard Mean Ocean Water (VSMOW) scale is often used for $\delta^{18} \mathrm{O}$ values of water, $\mathrm{CO}_{2}$ evolved from VPDB calcite (VPDB- $\mathrm{CO}_{2}$ scale) has similar $\delta^{18} \mathrm{O}$ values of $\mathrm{CO}_{2}$ equilibrated with VSMOW, which is the reference gas of the VSMOW scale. The difference between them is only $0.263 \%$ (IAEA, 1993; Kim et al., 2015). Additionally, corrections for 
(a)

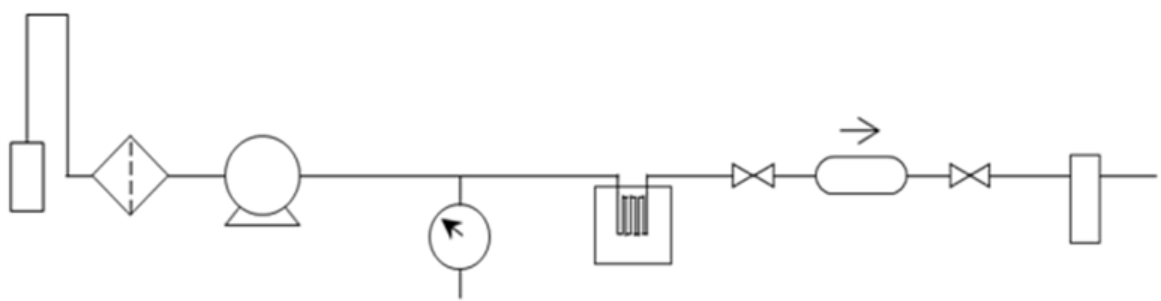

Inlet Filter Pump Back Pressure Cooler Valve Flasks Valve Flow $(7 \mu \mathrm{m})\left(2 \mathrm{~L} \mathrm{~min}^{-1}\right) \quad$ valve $\quad\left(-30^{\circ} \mathrm{C}\right) \quad$ meter

(b)

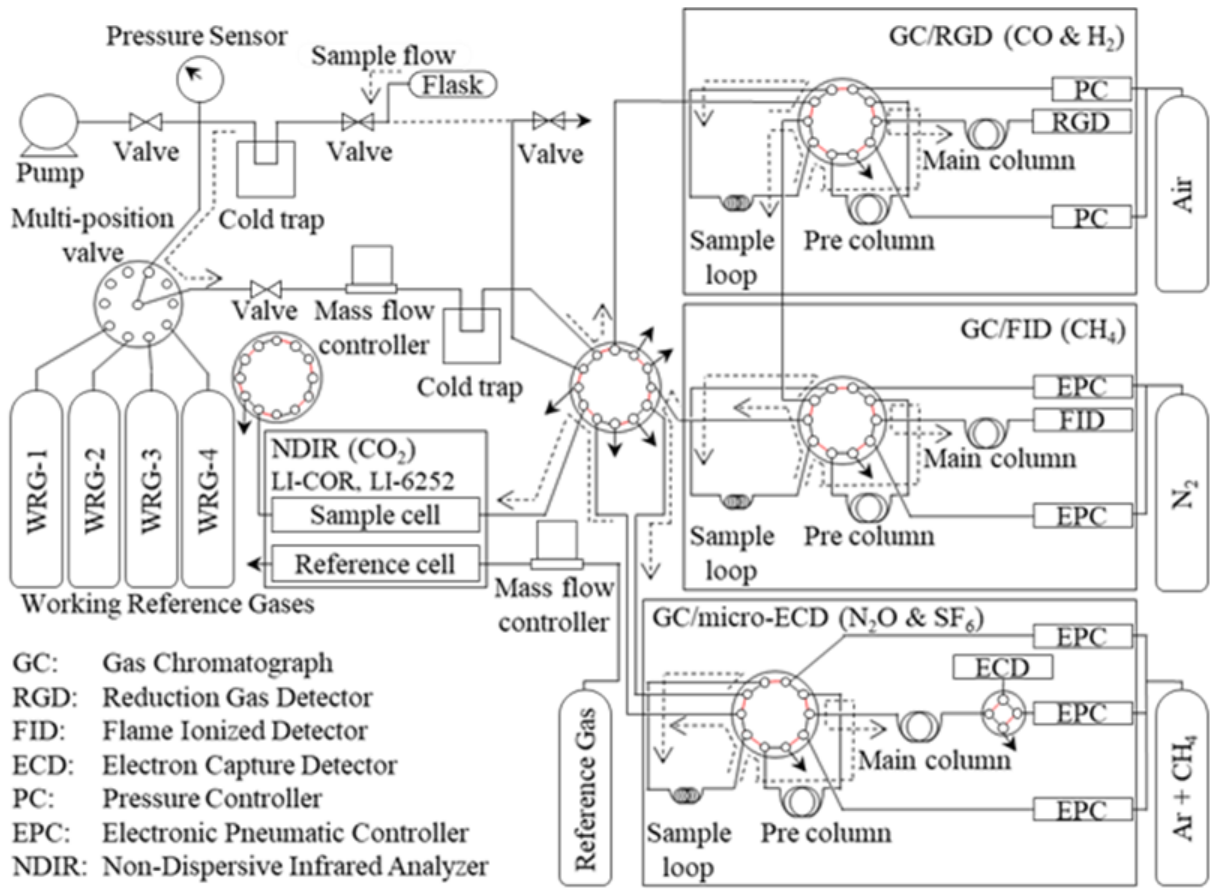

(c)

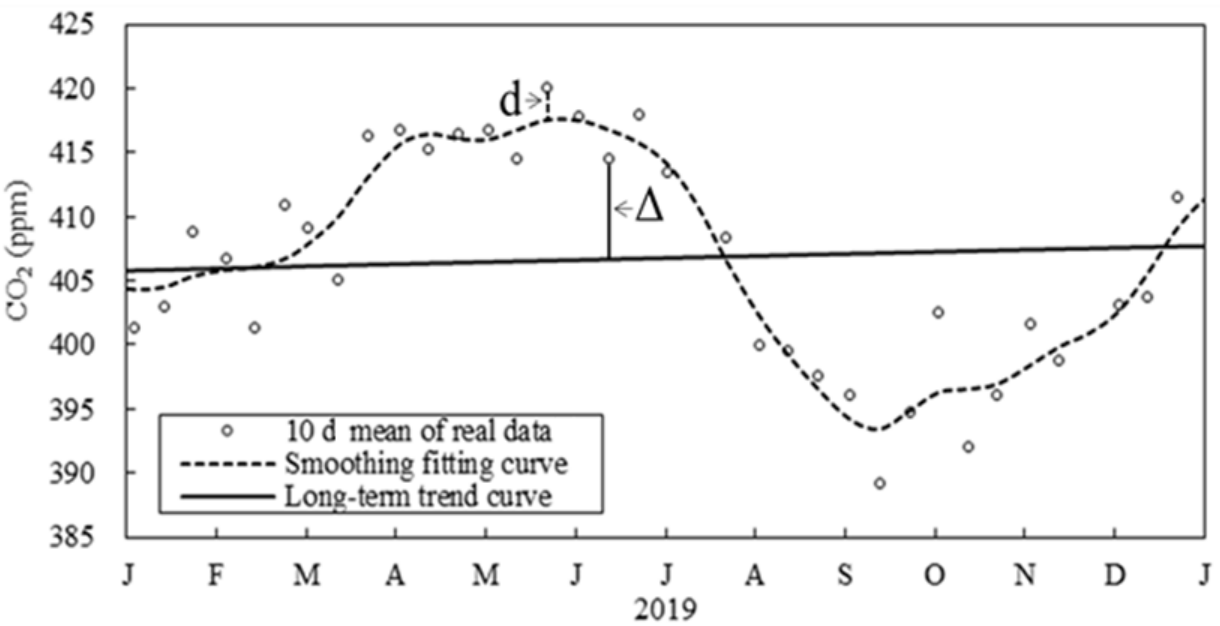

Figure 2. The line used for (a) flask sampling, (b) schematic of measurements of the dry-air mole fraction in the laboratory, and (c) diagram of the calculation method for the " $\Delta$ " term (e.g., $\Delta \mathrm{CO}_{2}$ ), which was calculated by subtraction of the long-term trend curve from the $10 \mathrm{~d}$ mean of real data and the "d" term (e.g., $\mathrm{dCO}_{2}$ ), which was characterized by the deviation of the $10 \mathrm{~d}$ mean of real data from the smoothing fitting curve. 
$\mathrm{N}_{2} \mathrm{O}$ bias and $\delta^{17} \mathrm{O}-\mathrm{CO}_{2}$ shown by Brand et al. (2010) were made to obtain final isotope ratios.

\subsection{Reference dataset}

For comparison with the data of NTL and CLA, we obtained weekly data $\left(\mathrm{CO}_{2}, \mathrm{CH}_{4}, \mathrm{CO}, \mathrm{N}_{2} \mathrm{O}, \mathrm{SF}_{6}, \delta^{13} \mathrm{C}_{-} \mathrm{CO}_{2}\right.$, and $\delta^{18} \mathrm{O}-\mathrm{CO}_{2}$ ) from the Mauna Loa Observatory (MLO) $\left(19.54^{\circ} \mathrm{N}, 155.58^{\circ} \mathrm{W} ; 3397 \mathrm{~m}\right.$ a.s.l.) on the NOAA/ESRL website (NOAA/ESRL, 2019b). We also used biweekly data for $\mathrm{CO}_{2}, \mathrm{CH}_{4}, \mathrm{CO}, \mathrm{H}_{2}, \mathrm{~N}_{2} \mathrm{O}$, and $\delta^{13} \mathrm{C}-\mathrm{CO}_{2}$ from CRI $\left(15.08^{\circ} \mathrm{N}, 73.83^{\circ} \mathrm{W} ; 60 \mathrm{~m}\right.$ a.s.l.) on the website of the World Data Centre for Greenhouse Gases (WDCGG) (WDCGG, 2017). The trends of mole fractions of $\mathrm{CO}_{2}, \mathrm{CH}_{4}, \mathrm{CO}, \mathrm{H}_{2}$, $\mathrm{N}_{2} \mathrm{O}$, and $\mathrm{SF}_{6}$ and the isotopic ratio of $\delta^{13} \mathrm{C}_{-}-\mathrm{CO}_{2}$ and $\delta^{18} \mathrm{O}$ $\mathrm{CO}_{2}$ were calculated according to the method of Thoning et al. (1989), with a cut-off frequency of $667 \mathrm{~d}(0.5472 \mathrm{cy}-$ cles $\mathrm{yr}^{-1}$ ) for a fast Fourier transform (FFT) filter. We also obtained the DMI and ENSO index from the NOAA/ESRL website (NOAA/ESRL, 2021a, b).

\subsection{Weather data}

Monthly precipitation data for Nainital use the monthly precipitation of the state of Uttarakhand, which includes Nainital. The data during January 2007 to December 2019 were taken from the rainfall report on the IMD (India Meteorological Department) website (available at: http://hydro.imd.gov.in/hydrometweb/ (S(fqu5hsvtq3sitn45ria4qma))/landing.aspx, last access: 1 September 2021). Monthly precipitation data for Comilla use the average monthly precipitation of the eastern IndoGangetic Plain in Bangladesh (Dhaka $\left(23.77^{\circ} \mathrm{N}, 90.38^{\circ} \mathrm{E}\right.$ and $8 \mathrm{~m}$ a.s.1.), Rangpur (25.73 $\mathrm{N}, 89.23^{\circ} \mathrm{E}$ and $33 \mathrm{~m}$ a.s.1.), Sylhet $\left(24.90^{\circ} \mathrm{N}, 91.88^{\circ} \mathrm{E}\right.$ and $34 \mathrm{~m}$ a.s.l.), Bogra $\left(24.84^{\circ} \mathrm{N}\right.$, $89.37^{\circ} \mathrm{E}$ and $18 \mathrm{~m}$ a.s.l.), Ishurdi $\left(24.13^{\circ} \mathrm{N}, 89.05^{\circ} \mathrm{E}\right.$ and $13 \mathrm{~m}$ a.s.1.), Jessore $\left(23.18^{\circ} \mathrm{N}, 89.17^{\circ} \mathrm{E}\right.$ and $\left.6 \mathrm{ma.s.1.}\right)$, Feni $\left(23.03^{\circ} \mathrm{N}, 91.42^{\circ} \mathrm{E}\right.$ and $6 \mathrm{~m}$ a.s.1.), Barisal $\left(22.75^{\circ} \mathrm{N}\right.$, $90.37^{\circ} \mathrm{E}$ and $3 \mathrm{~m}$ a.s.1.), Chattoogram $\left(22.27^{\circ} \mathrm{N}, 91.82^{\circ} \mathrm{E}\right.$ and $4 \mathrm{~m}$ a.s.1.), and Cox's Bazar $\left(21.43^{\circ} \mathrm{N}, 91.93^{\circ} \mathrm{E}\right.$ and 2 ma.s.l.)). Data during January 2012 to July 2021 were taken from the JMA (Japan Meteorological Agency) website (available at: http://www.data.jma.go.jp/gmd/cpd/monitor/ climatview/frame.php?y=2019\&m=7\&d=30\&e=0, last access: 1 September 2021).

\subsection{Back-trajectory analysis}

To determine the sources of regional air masses affecting the stations (NTL and CLA), we calculated backward air trajectories using the Meteorological Data Explorer (METEX) system (Zeng and Fujinuma, 2004) available via the website of the Center for Global Environmental Research, National Institute for Environmental Studies (available at: http: //db.cger.nies.go.jp/metex/index.html, last access: 1 September 2021). METEX uses three-dimensional wind speed (hor- izontal and vertical wind) estimated from the European Centre for Medium-Range Weather Forecast (ECMWF) analyses on a $0.5^{\circ} \times 0.5^{\circ}$ mesh to calculate $72 \mathrm{~h}$ trajectories. We use $1940 \mathrm{~m}$ for NTL and $30 \mathrm{~m}$ for CLA as the starting heights. We referred to the altitude data when we evaluated the effects of GHG emissions sources near the surface.

The ratio of air mass from the south per year was calculated by the frequency of the air mass from the southern side of the Indian Ocean on the flask sampling date in each year with reference to the $72 \mathrm{~h}$ backward air trajectory data calculated by METEX.

\subsection{Data analysis method for the short term and long term}

Mean values for every $10 \mathrm{~d}$ were calculated from the weekly data and were used to calculate the long-term trend and smoothing fitting curve. Because the sampling interval is not punctual and we sometimes had missing data, we decided to use the $10 \mathrm{~d}$ average to calculate the trend curve. The value of the missing period was supplemented with an interpolated value from the previous and following data of the missing period for calculating the continuous long-term trend and smoothing fitting curve.

Long-term trends of the mole fractions were calculated based on the idea of Thoning et al. (1989) with a cut-off frequency of $667 \mathrm{~d}\left(0.5472\right.$ cycles $\left.\mathrm{yr}^{-1}\right)$ for a FFT filter. The smoothing fitting curve was made for a FFT filter with a cutoff frequency of $50 \mathrm{~d}\left(7.3\right.$ cycles $\left.\mathrm{yr}^{-1}\right)$.

We defined and expressed the seasonal component by a " $\Delta$ " term (e.g., $\Delta \mathrm{CO}_{2}$ ) which was calculated by subtraction of the long-term trend curve from a $10 \mathrm{~d}$ mean of real data. Also, we defined and expressed short-term variations by a "d" term (e.g., $\mathrm{dCO}_{2}$ ), which were characterized by the deviation of a $10 \mathrm{~d}$ mean of real data from the smoothing fitting curve. Figure $2 \mathrm{c}$ shows how such components were calculated. Growth rates of mole fractions of observed gases were calculated using the long-term trends.

\section{Results and discussion}

\subsection{Overview of GHG mole fractions at both sites}

Basically, the air masses over the Indian subcontinent were transported from the Indian Ocean region during summer (monsoon season) and from the inland during winter. Air mass trajectories are shown for our sampling sites and related sites in Fig. 3. In the case of anthropogenic GHGs, except $\mathrm{CO}_{2}$, their mole fractions at CLA generally showed relatively low values when the air mass came from the ocean, while the mole fractions were relatively high when the air mass came from inland. On the other hand, mole fractions of GHGs at NTL overall did not show relatively low values even if the air mass came from the Indian Ocean region (i.e., southeasterly wind) because the air mass from the Indian Ocean was 
strongly affected by local GHG emissions while passing over the Indo-Gangetic Plain. However, the $\mathrm{CO}_{2}$ mole fraction changed not only due to transport, but also due to the photosynthetic sink strength of terrestrial ecosystems and cultivated crops.

Annual mean GHG mole fractions at NTL and CLA are summarized in Table 1. Annual $\mathrm{CO}_{2}$ mole fractions at both sites were quite low compared to MLO and other Indian sites such as CRI. For example, in 2010, 386.5 ppm was reported at NTL, $391.9 \mathrm{ppm}$ at CRI (Bhattacharya et al., 2009), and $391.3 \mathrm{ppm}$ at PON (Lin et al., 2015). Note that there are no data for CLA in 2010; however, the annual $\mathrm{CO}_{2}$ mole fraction at CLA is usually only 1-2 ppm higher than at NTL. This seemed to be due to the influence of photosynthesis at both sites. Generally, the $\mathrm{CO}_{2}$ mole fractions at NTL and CLA decreased strongly (typically twice a year) due to photosynthesis of local crops, making the annual $\mathrm{CO}_{2}$ mole fractions lower than at other sites despite the likelihood that anthropogenic emissions are high in this area.

On the other hand, the annual mean mole fractions of $\mathrm{CH}_{4}$, $\mathrm{CO}, \mathrm{H}_{2}$, and $\mathrm{N}_{2} \mathrm{O}$ at NTL and CLA (Table 1) were almost at the highest levels on the Indian subcontinent due to the influence of strong emission sources. For example, the annual mole fractions of NTL and CLA were 50-470 ppb for $\mathrm{CH}_{4}$, 30-200 ppb for $\mathrm{CO}$, and 0-5 ppb for $\mathrm{N}_{2} \mathrm{O}$ higher compared to other Indian sites (e.g., CRI, Bhattacharya et al., 2009; HLE, PON, and PBL, Lin et al., 2015). In this region, high $\mathrm{CH}_{4}$ and $\mathrm{N}_{2} \mathrm{O}$ emissions were possible from paddy fields and cultivated areas. Also, much $\mathrm{CO}$ is considered to be produced by biomass burning in this region. As for $\mathrm{H}_{2}$, the mole fraction at CLA was higher than those at other Indian sites; however, it was relatively low at NTL compared to other sites such as CRI (Bhattacharya et al., 2009), PON, and PBL (Lin et al., 2015) but similar to HLE, which is located on a higher mountain. In the case of the $\mathrm{SF}_{6}$ mole fraction, it has smaller regional differences, suggesting there are no remarkable $\mathrm{SF}_{6}$ sources near the measurement sites. Below we describe in detail the characteristics of sources and sinks of each component $\left(\mathrm{CO}_{2}, \delta^{13} \mathrm{C}-\mathrm{CO}_{2}, \delta^{18} \mathrm{O}-\mathrm{CO}_{2} \mathrm{CH}_{4}, \mathrm{CO}, \mathrm{H}_{2}, \mathrm{~N}_{2} \mathrm{O}\right.$, and $\mathrm{SF}_{6}$ ) at NTL and CLA on the Indo-Gangetic Plain in terms of seasonal variations, amplitudes, and growth rates.

\section{$3.2 \mathrm{CO}_{2}$ and $\delta^{13} \mathrm{C}-\mathrm{CO}_{2}$}

\subsection{1 $\mathrm{CO}_{2}$ mole fraction and growth rate variations}

Figure 4 shows the time series of the atmospheric $\mathrm{CO}_{2}$ mole fraction and the isotopic ratio of $\delta^{13} \mathrm{C}-\mathrm{CO}_{2}$ at our sampling sites (NTL and CLA) together with data from CRI on the western coast of India and MLO in Hawaii. The $\mathrm{CO}_{2}$ mole fractions at NTL and CLA in August-October were characteristically lower (approximately 10-20 ppm) than the mole fractions observed at CRI and MLO. The CRI and MLO sites are representative of $\mathrm{CO}_{2}$ mole fractions in the Southern Hemisphere and Northern Hemisphere, respec- tively, for the period of the southwestern monsoon season (June-September). On the other hand, the $\delta^{13} \mathrm{C}-\mathrm{CO}_{2}$ at NTL and CLA was inversely correlated with the $\mathrm{CO}_{2}$ mole fractions, and generally the values at both sites were higher than at MLO and CRI.

Air masses at NTL and CLA in August-October passed over the Indo-Gangetic Plain and the southeastern area of India, respectively, while the air masses of CRI were transported from the Indian Ocean region (Fig. 3). Thus, it was suggested that the air mass from the Indian Ocean in AugustOctober prevailing over CRI was hardly influenced by anthropogenic emission and photosynthesis over the Indian subcontinent, whereas $\mathrm{CO}_{2}$ mole fractions over NTL and CLA seemed to be influenced during these seasons by the sources and sinks on the Indo-Gangetic Plain and the southern/eastern areas of the Indian subcontinent. Such transport characteristics must affect the annual average and growth rates in the $\mathrm{CO}_{2}$ molar ratio and $\delta^{13} \mathrm{C}-\mathrm{CO}_{2}$ in addition to their seasonal variations.

We show the $\mathrm{CO}_{2}$ growth rates observed at NTL, CLA, and MLO in Fig. 5a. Mean $\mathrm{CO}_{2}$ growth rates at NTL (ap-

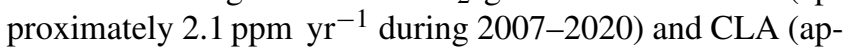
proximately $2.9 \mathrm{ppm} \mathrm{yr}^{-1}$ during 2013-2020) were similar to other sites (e.g., MLO). However, variations of the calculated growth rates were greater than those at MLO. The range was $0-5 \mathrm{ppm} \mathrm{yr}^{-1}$ in the case of NTL, and CLA had higher variability than NTL because local sink and source influences affected the concentration more than remote sites such as MLO. In general, Pacific sites such as MLO and Japanese remote sites in the Northern Hemisphere showed a relationship between $\mathrm{CO}_{2}$ growth rates and the ENSO index (e.g., Keeling, 1998). This relationship is often explained from the viewpoint of a global temperature anomaly, which has a strong relationship with the ENSO index. On the other hand, the variability at NTL has no associations with the variability in the $\mathrm{CO}_{2}$ growth rate at MLO and the ENSO index (Fig. 5b). Both growth rates seemed to be slightly inversely correlated with each other from 2007 to 2015 . However, since then, similar relatively high growth rates have been observed for both sites around 2015-2016 and 20182019, indicating that, overall, the $\mathrm{CO}_{2}$ growth rate at NTL is less correlated with the $\mathrm{CO}_{2}$ growth rate at MLO and the ENSO index.

It is well known that the Indian Ocean Dipole controls meteorological conditions such as air mass transportation and precipitation patterns on the Indian subcontinent (e.g., Saji et al., 1999; Ashok et al., 2004; Hong et al., 2008). Such changes in regional climatic pattern could affect the $\mathrm{CO}_{2}$ uptake flux by plants in the surrounding area and the atmospheric movement, leading to a change in the $\mathrm{CO}_{2}$ growth rate. However, we did not find a simple relationship between DMI and $\mathrm{CO}_{2}$ growth rate at NTL (Fig. 5b). Here we have shown that the pattern of $\mathrm{CO}_{2}$ growth rate in this region is different from the global pattern seen in places like MLO, but the relationship between local climatic factors and changes in 


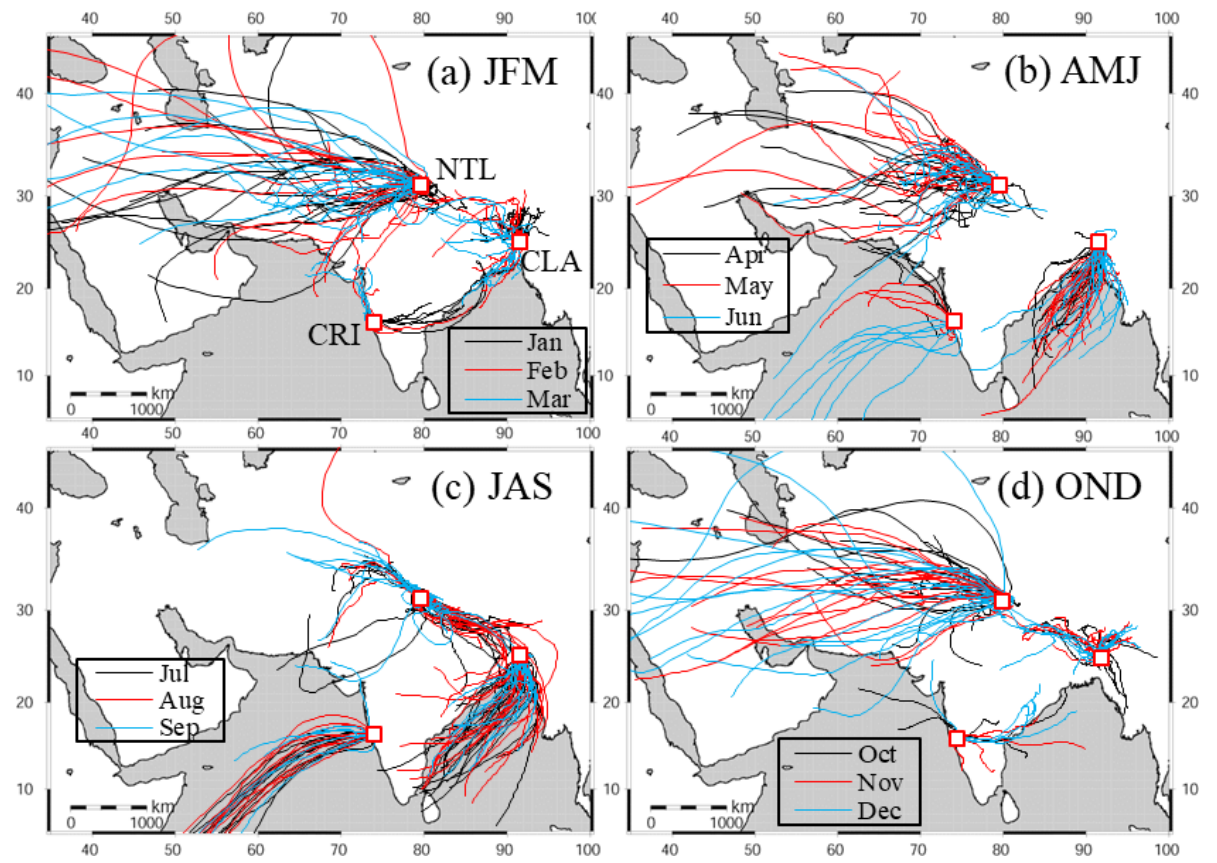

Figure 3. $72 \mathrm{~h}$ back-trajectory of NTL, CLA, and CRI in (a) January-March (JFM), (b) April-June (AMJ), (c) July-September (JAS), and (d) October-December; $72 \mathrm{~h}$ back-trajectory at NTL and CLA shown for 2012-2016 and the back-trajectory at CRI shown for 2009-2013.

Table 1. Annual mean atmospheric mole fractions of $\mathrm{CO}_{2}, \mathrm{CH}_{4}, \mathrm{CO}, \mathrm{H}_{2}, \mathrm{~N}_{2} \mathrm{O}$, and $\mathrm{SF}_{6}$, isotopic ratios of $\delta^{13} \mathrm{C}_{-} \mathrm{CO}_{2}$ and $\delta^{18} \mathrm{O}-\mathrm{CO}_{2}$, and $\mathrm{CO}_{2}$ growth rates at Nainital (NTL) and Comilla (CLA) in 2007-2020.

\begin{tabular}{|c|c|c|c|c|c|c|c|c|c|c|c|c|c|c|c|c|c|c|c|}
\hline \multirow[t]{2}{*}{ Site } & \multirow[t]{2}{*}{ Year } & \multicolumn{2}{|c|}{$\begin{array}{l}\mathrm{CO}_{2} \\
\mathrm{ppm}\end{array}$} & \multicolumn{2}{|c|}{$\begin{array}{l}\mathrm{CH}_{4} \\
\mathrm{ppb}\end{array}$} & \multicolumn{2}{|c|}{$\begin{array}{l}\mathrm{CO} \\
\mathrm{ppb}\end{array}$} & \multicolumn{2}{|c|}{$\begin{array}{l}\mathrm{H}_{2} \\
\mathrm{ppb}\end{array}$} & \multicolumn{2}{|c|}{$\begin{array}{c}\mathrm{N}_{2} \mathrm{O} \\
\mathrm{ppb}\end{array}$} & \multicolumn{2}{|c|}{$\begin{array}{c}\mathrm{SF}_{6} \\
\mathrm{ppt}\end{array}$} & \multicolumn{2}{|c|}{$\begin{array}{c}\delta^{13} \mathrm{C}-\mathrm{CO}_{2} \\
\% o\end{array}$} & \multicolumn{2}{|c|}{$\begin{array}{c}\delta^{18} \mathrm{O}-\mathrm{CO}_{2} \\
\% o\end{array}$} & \multicolumn{2}{|c|}{$\begin{array}{c}\mathrm{CO}_{2} \\
\text { growth rate }\end{array}$} \\
\hline & & Avg & SD & Avg & SD & Avg & SD & Avg & SD & Avg & SD & Avg & SD & Avg & SD & Ave & SD & Avg & SD \\
\hline Nainital & 2007 & 380.6 & 9.6 & 1928.4 & 70.6 & 238.7 & 100.5 & 546.1 & 19.7 & 321.9 & 0.83 & 6.25 & 0.17 & -8.14 & 0.44 & 0.72 & 1.09 & & \\
\hline Nainital & 2008 & 3.2 & 7.8 & 1931.0 & 75.5 & 225.4 & 99.4 & 551.8 & 24.1 & 323.0 & 0.83 & 6.57 & 0.29 & -8.15 & 0.35 & 0.50 & 1.00 & -0.4 & 0.95 \\
\hline Nainital & 2009 & 383.5 & 9.3 & 1919.4 & 63.3 & 210.2 & 79.2 & 538.8 & 28.0 & 323.7 & 0.88 & 6.95 & 0.28 & -8.13 & 0.44 & 0.55 & 0.87 & 3.3 & 0.76 \\
\hline Nainital & 2010 & 386.5 & 9.0 & 25.7 & 59.7 & 214.4 & 92.6 & 537.9 & 25.6 & 324.7 & 0.87 & 7.19 & 0.24 & -8.19 & 0.42 & 0.28 & 1.13 & 0.7 & 0.28 \\
\hline Nainital & 2011 & 389.6 & 6.3 & 1945.2 & 70.3 & 213.7 & 72.1 & 544.6 & 24.5 & 325.4 & 0.97 & 7.52 & 0.21 & -8.28 & 0.32 & 0.35 & 1.20 & 2.3 & 0.78 \\
\hline Nainital & 2012 & 391.2 & 7.5 & 1956.0 & 76.7 & 222.1 & 79.3 & 552.6 & 29.9 & 326.2 & 1.18 & 7.85 & 0.35 & -8.22 & 0.33 & 0.31 & 1.12 & 4.1 & 0.74 \\
\hline Nainital & 2013 & 391.7 & 8.0 & 1963.1 & 58.2 & 223.2 & 69.7 & 549.9 & 24.8 & 327.2 & 1.03 & 8.11 & 0.15 & -8.19 & 0.39 & 0.47 & 1.29 & 0.1 & 0.92 \\
\hline Nainital & 2014 & 394.3 & 7.5 & 1961.2 & 75.4 & 205.5 & 66.0 & 543.0 & 22.9 & 328.3 & 1.17 & 8.48 & 0.16 & -8.25 & 0.34 & 0.92 & 0.93 & 1.3 & 0.76 \\
\hline Nainital & 2015 & 396.0 & 8.3 & 1984.1 & 72.8 & 226.6 & 77.1 & 549.3 & 28.1 & 329.4 & 1.02 & 8.84 & 0.23 & -8.24 & 0.38 & 1.04 & 0.87 & 2.3 & 1.55 \\
\hline Nainital & 16 & 400.8 & 8. & 1990.0 & 62.8 & 227.6 & 77.7 & 557.1 & & 329.9 & & 9.05 & 0.14 & -8.36 & 0.39 & 0.92 & 1.10 & 3.6 & 1.83 \\
\hline Nainital & 2017 & 401.6 & 8.5 & 2012.1 & 83.8 & 229.0 & 77.8 & 555.9 & 26.3 & 331.0 & 1.24 & 9.43 & 0.16 & -8.28 & 0.41 & 0.90 & 1.08 & 2.8 & 1.00 \\
\hline Nainital & 2018 & 404.3 & 7.8 & 2013.8 & 67.9 & 225.1 & 82.8 & 559.7 & 33.2 & 332.2 & 0.95 & 9.74 & 0.14 & -8.36 & 0.36 & 0.91 & 1.10 & 1.4 & 0.31 \\
\hline Nainital & 2019 & 406.3 & 8.8 & 2021.3 & 64.1 & 232.4 & 84.3 & 556.8 & 29.5 & 332.7 & 1.08 & 10.10 & 0.13 & -8.36 & 0.40 & 0.81 & 1.19 & 3.1 & 0.84 \\
\hline Nainital & 2020 & 407.4 & 6.7 & 2037.3 & 88.2 & 206.8 & 75.0 & 563.8 & 48.8 & 334.0 & 1.32 & 10.43 & 0.17 & -8.33 & 0.31 & 0.66 & 1.21 & & \\
\hline Comilla & 013 & 3.7 & 9.0 & 14.6 & 91.6 & 294.7 & 168.8 & 607.7 & 69.3 & 28.4 & 2.29 & 8.12 & 0.18 & -8.41 & 0.38 & 0.42 & 0.95 & 4.6 & 1.73 \\
\hline Comilla & 2014 & 395.4 & 10.8 & 2274.0 & 402.3 & 318.6 & 162.2 & 612.1 & 53.7 & 330.0 & 2.36 & 8.46 & 0.16 & -8.44 & 0.45 & 0.52 & 0.82 & -1.4 & 0.95 \\
\hline Comilla & 2015 & 395.6 & 7.2 & 2272.4 & 250.6 & 293.8 & 118.4 & 596.0 & 32.6 & 330.5 & 1.87 & 8.78 & 0.13 & -8.34 & 0.32 & 0.44 & 0.87 & 5.0 & 2.70 \\
\hline Comilla & 2016 & 402.4 & 8.1 & 2363.3 & 399.5 & 292.5 & 119.9 & 652.5 & 81.0 & 330.9 & 1.75 & 9.01 & 0.16 & -8.54 & 0.35 & 0.11 & 1.17 & 4.2 & 1.85 \\
\hline Comilla & 2017 & 404.6 & 8.8 & 2484.5 & 450.1 & 293.4 & 129.2 & 601.9 & 27.6 & 332.1 & 2.29 & 9.37 & 0.19 & -8.54 & 0.38 & -0.14 & 1.23 & 1.8 & 1.79 \\
\hline Comilla & 2018 & 403.8 & 8.1 & 2380.0 & 253.4 & 295.7 & 135.4 & 669.3 & 85.6 & 333.0 & 1.82 & 9.68 & 0.10 & -8.47 & 0.34 & 0.16 & 0.86 & 0.5 & 3.05 \\
\hline Comilla & 2019 & 408.9 & 7.9 & 2406.7 & 331.5 & 284.5 & 114.0 & 604.6 & 36.9 & 333.9 & 1.81 & 10.07 & 0.16 & -8.58 & 0.33 & -0.06 & 1.44 & 5.5 & 0.90 \\
\hline Comilla & 2020 & 415.2 & 11.2 & 2830.6 & 679.6 & 339.9 & 167.4 & 639.0 & 91.8 & 336.0 & 3.08 & 10.46 & 0.24 & -8.73 & 0.50 & -0.31 & 1.15 & & \\
\hline
\end{tabular}

$\mathrm{CO}_{2}$ sinks and emissions is likely to be complex, and further study is needed to interpret the differences.

\subsubsection{Seasonal variation and its characteristics}

Figure 6a-d show the seasonal variations in $\mathrm{CO}_{2}$ mole fractions and isotopic ratios of $\delta^{13} \mathrm{C}-\mathrm{CO}_{2}$ at NTL, CLA, CRI, and MLO, which were calculated by subtraction of the measured value from the long-term trend. The annual amplitudes of the 


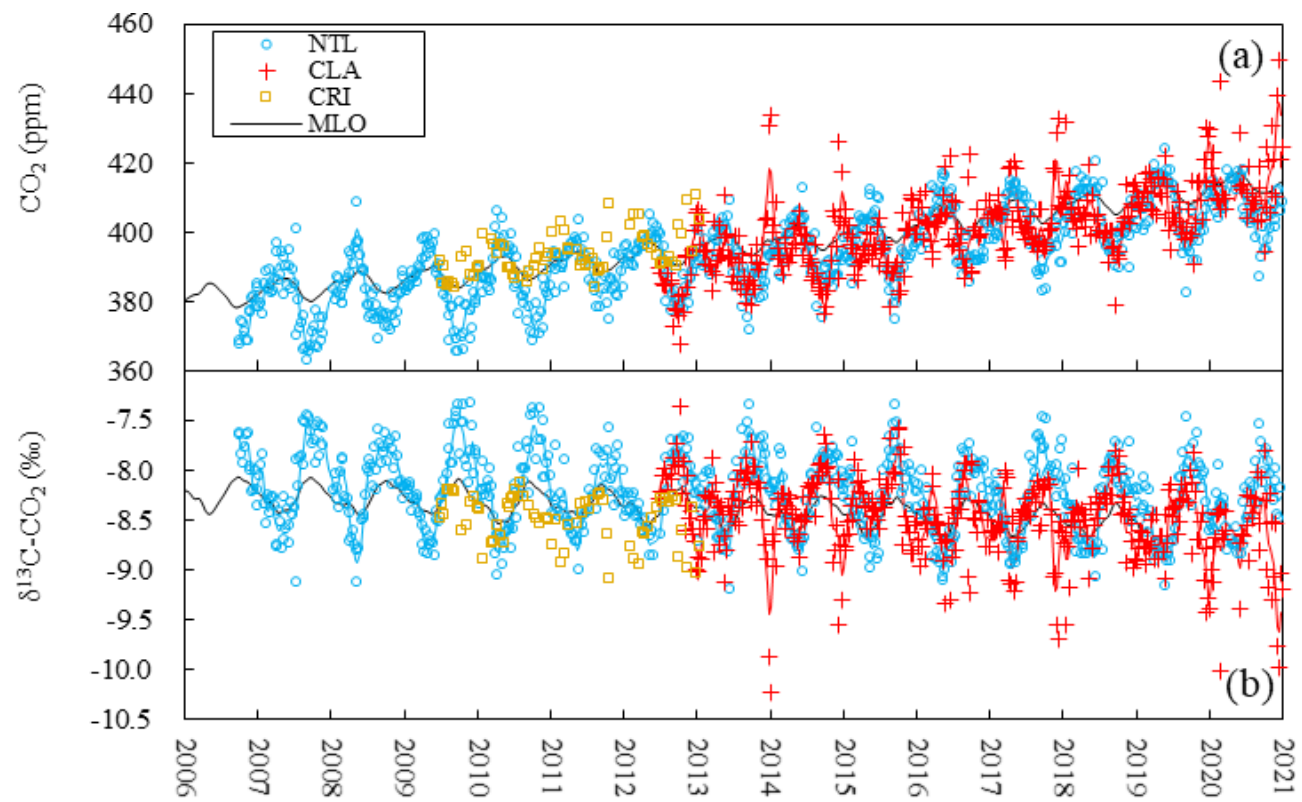

Figure 4. Time series of the (a) atmospheric $\mathrm{CO}_{2}$ mole fraction and the (b) isotope ratio of $\delta^{13} \mathrm{C}-\mathrm{CO} 2$ at NTL, CLA, CRI, and MLO in 2006-2020.

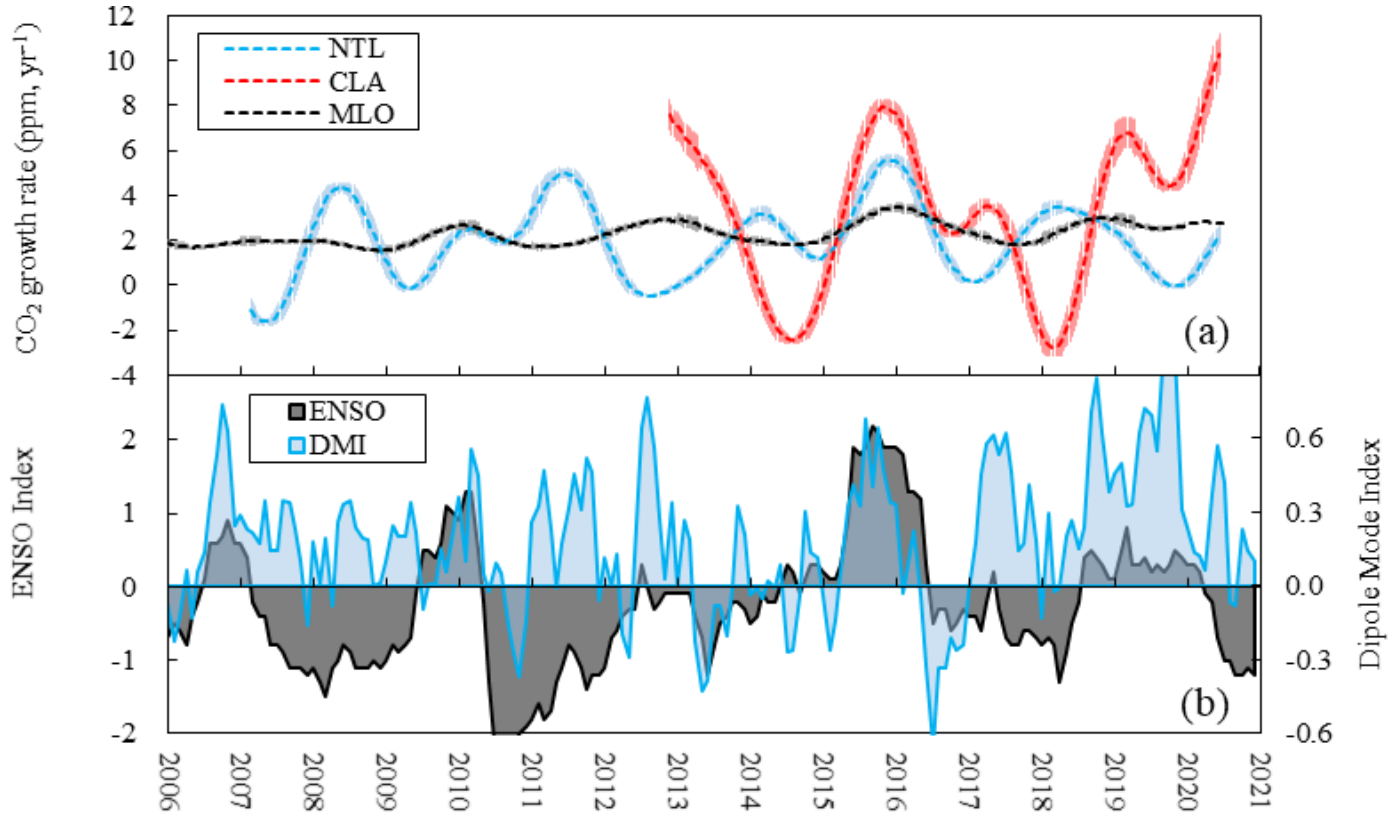

Figure 5. (a) Growth rates of the $\mathrm{CO}_{2}$ mole fraction at NTL, CLA, and MLO in 2006-2020 and (b) the El Niño-Southern Oscillation (ENSO) index in 2006-2020 and the Dipole Mode Index (DMI) in 2006-2020.

$\mathrm{CO}_{2}$ mole fraction (Table 2) at NTL $(22.1 \pm 3.9 \mathrm{ppm})$ and CLA $(20.3 \pm 5.7 \mathrm{ppm})$ were much larger than those at other Indian sites (CRI, $15 \mathrm{ppm}$; HLE, $8.2 \mathrm{ppm}$; PON, $7.6 \mathrm{ppm}$; PBL, $11.1 \mathrm{ppm})$. Also, the annual amplitudes of $\delta^{13} \mathrm{C}_{-} \mathrm{CO}_{2}$ at NTL $(0.96 \%$ $\pm 0.16 \%$ ) and CLA $(0.85 \%$ $\pm 0.19 \%$ ) were larger than that at CRI (approximately $0.6 \%$ o). These results suggested that the atmospheric $\mathrm{CO}_{2}$ mole fractions of NTL and CLA were strongly influenced by photosynthesis of lo- cal plants in summer and their respiration in winter and other anthropogenic emissions which were moderated at the other sites by the influence of the oceanic air. Also, small episodic peaks of the atmospheric $\mathrm{CO}_{2}$ mole fraction and isotopic ratio of $\delta^{13} \mathrm{C}-\mathrm{CO}_{2}$ of CLA at the beginning of each year were influenced by the biomass burning for heating in the close region, which is considered to be the inland area from the site according to the air trajectory analysis. 
Table 2. Mean annual amplitudes of seasonal variation in atmospheric mole fractions of $\mathrm{CO}_{2}, \mathrm{CH}_{4}, \mathrm{CO}, \mathrm{H}_{2}, \mathrm{~N}_{2} \mathrm{O}$, and $\mathrm{SF}_{6}$ and $\delta{ }^{13} \mathrm{C}-\mathrm{CO}_{2}$ and $\delta^{18} \mathrm{O}-\mathrm{CO}_{2}$ at NTL during 2007-2020 and at CLA during 2013-2020.

\begin{tabular}{lcccccccc}
\hline Site & $\begin{array}{c}\mathrm{CO}_{2} \\
\mathrm{ppm}\end{array}$ & $\begin{array}{c}\mathrm{CH}_{4} \\
\mathrm{ppb}\end{array}$ & $\begin{array}{c}\mathrm{CO} \\
\mathrm{ppb}\end{array}$ & $\begin{array}{c}\mathrm{H}_{2} \\
\mathrm{ppb}\end{array}$ & $\begin{array}{c}\mathrm{N}_{2} \mathrm{O} \\
\mathrm{ppb}\end{array}$ & $\begin{array}{c}\mathrm{SF}_{6} \\
\mathrm{ppt}\end{array}$ & $\begin{array}{c}\delta^{13} \mathrm{C}_{-} \mathrm{CO}_{2} \\
\% o\end{array}$ & $\begin{array}{c}\delta^{18} \mathrm{O}_{-} \mathrm{CO}_{2} \\
\% o\end{array}$ \\
\hline Nainital & $22.1 \pm 3.9$ & $114 \pm 52$ & $153 \pm 44$ & $50.3 \pm 18.0$ & $1.01 \pm 0.74$ & $0.18 \pm 0.16$ & $0.96 \pm 0.16$ & $2.71 \pm 0.79$ \\
Comilla & $20.3 \pm 5.7$ & $486 \pm 225$ & $356 \pm 90$ & $70.4 \pm 41.2$ & $4.25 \pm 1.45$ & $0.23 \pm 0.08$ & $0.85 \pm 0.19$ & $2.33 \pm 0.49$ \\
\hline
\end{tabular}
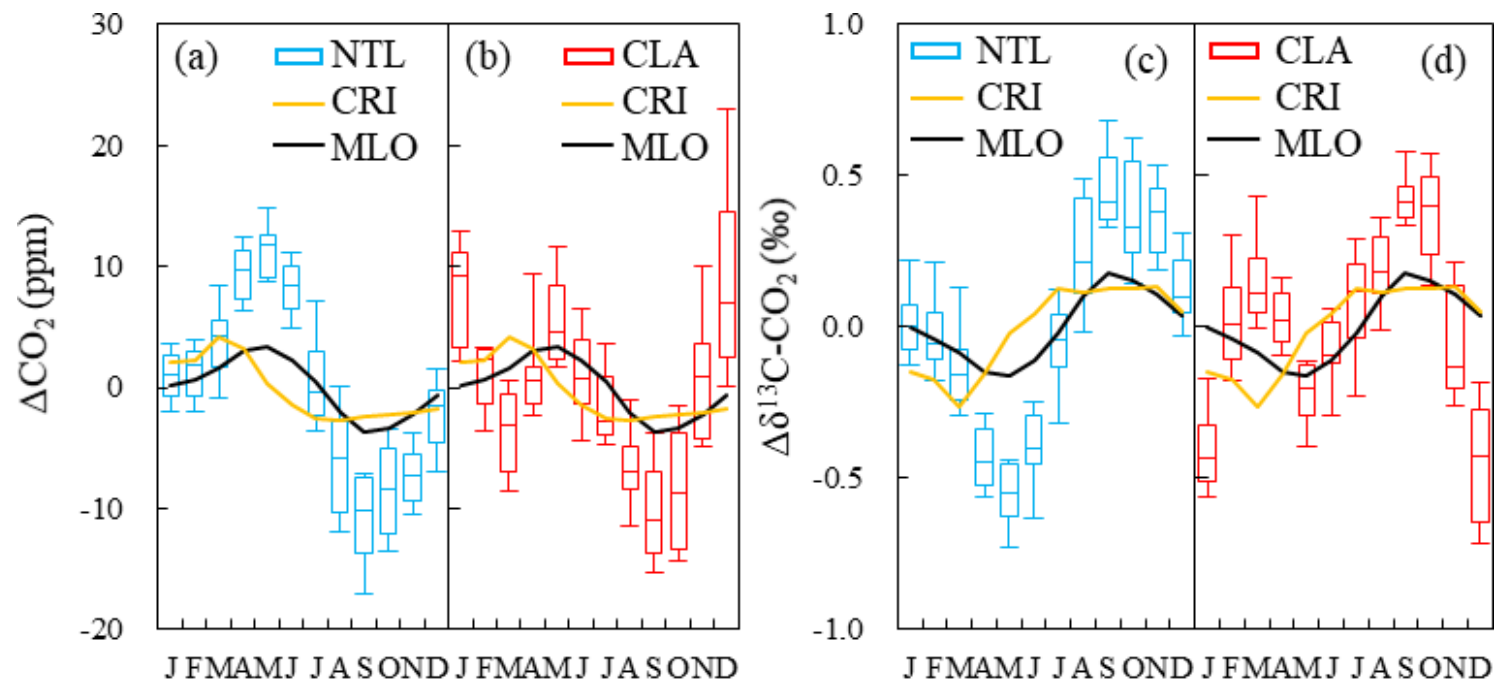

Month

Figure 6. Seasonal variations in the $\mathrm{CO}_{2}$ mole fraction at (a) NTL and (b) CLA and the isotope ratio of $\delta^{13} \mathrm{C}-\mathrm{CO} 2$ at (c) NTL and (d) CLA. Boxes with blue and red are for Nainital and Comilla, and the black and yellow lines are for MLO and CRI, respectively. Median values (the line in the box) and the inner 50th percentile of the value (box) and inner 90th percentile of the value are from the monthly averaged $\mathrm{CO}_{2}$ mole fractions.

As shown in Figs. $4 a$ and $b$ and $6 b$ and $d$, the seasonal variation pattern at CLA has two lower seasons in $\mathrm{CO}_{2}$ and two higher seasons in $\delta^{13} \mathrm{C}-\mathrm{CO}_{2}$ in February-April and JulyOctober. Similarly, in the case of NTL, we sometimes observed relatively low mole fractions of $\mathrm{CO}_{2}$ in FebruaryMarch and September and higher $\delta^{13} \mathrm{C}-\mathrm{CO}_{2}$. In general, in many cases, including at MLO, only a summer minimum $\mathrm{CO}_{2}$ mole fraction is observed, while a minimum in February-March is not usually observed.

Twice-yearly decreases in the $\mathrm{CO}_{2}$ mole fraction have also been observed at several Indian sites such as Dehradun (northern Indian site; Sharma et al., 2013), Sinhagad (western Ghats site; Tiwari et al., 2014), Ahmedabad (western Indian site; Chandra et al., 2016), Shadnagar (central Indian site; Sreenivas et al., 2016), and PON (southeastern coastal Indian site; Lin et al., 2015); however, these studies did not clearly mention such variations. Umezawa et al. (2016) reported that the decrease in the $\mathrm{CO}_{2}$ mole fraction near the ground in February-March was caused by photosynthesis of local crops, which was detected by the vertical $\mathrm{CO}_{2}$ profiles over New Delhi Airport. Those sites are located on the IndoGangetic Plain or received air masses passing over the Indo-
Gangetic Plain or Indian subcontinent. On the other hand, the decrease in the $\mathrm{CO}_{2}$ mole fraction in February-March was not detected at CRI (western coastal Indian site; Bhattacharya et al., 2009), HLE (northwestern Himalayan site), or PBL (Andaman Islands site) (Lin et al., 2015). These sites are not located on the Indo-Gangetic Plain. Thus, air masses at these sites must be mainly transported from the ocean or from areas other than the Indian subcontinent during these periods.

The characteristic $\mathrm{CO}_{2}$ seasonal variation on the IndoGangetic Plain (including NTL and CLA) is very likely to be related to $\mathrm{CO}_{2}$ uptake by regional vegetation. Generally, in the case of the state of Uttar Pradesh located in the center of the Indo-Gangetic Plain, rice and other summer plants (maize, millets, etc.) are planted mainly in June-July and harvested in October-November, while large areas of wheat are sown in October-December and harvested in March-April. Therefore, relatively low $\mathrm{CO}_{2}$ mole fractions observed in those periods are considered to be due to $\mathrm{CO}_{2}$ uptake by plants cultivated in each season near NTL.

In Bangladesh, rice, being the staple food, is cultivated three times a year in some regions. Usually rice is grown 
twice (aus and amon rice) from April to October (including the monsoon season); however, rice is also often cultivated (boro rice) in the winter season from November to April (SID/MP, 2018). Other agricultural products include maize, jute, and vegetables in the summer season and a small amount of wheat in the winter season. Therefore, we concluded that the observed lower $\mathrm{CO}_{2}$ mole fractions in JulyOctober and February-March were influenced by $\mathrm{CO}_{2}$ uptake by local plants (mainly rice). Especially at CLA, the lower mole fraction in February-March was clear, and a strong contribution from $\mathrm{CO}_{2}$ uptake from boro rice was estimated. As another viewpoint on $\mathrm{CO}_{2}$ seasonal variation, we observed that the $\mathrm{CO}_{2}$ maximum in May was not so high, while the $\mathrm{CO}_{2}$ mole fraction in December was higher. Because precipitation in Bangladesh is stronger than in the northern Indian region, the duration of rice cultivation over summertime is also longer than in northern India. Therefore, the contribution of plant uptake to the $\mathrm{CO}_{2}$ mole fraction in the atmosphere at CLA over the summer season is likely to be relatively large compared to that at NTL.

Thus, the decreases in the $\mathrm{CO}_{2}$ mole fractions in February-March and September in NTL and CLA were estimated to be caused by photosynthesis of plants cultivated in each season over the Indo-Gangetic Plain. NTL and CLA indicated this more clearly compared with other Indian sites due to the proximity to the source region. Figure 7 a shows the relationships between the annual mean $\mathrm{CO}_{2}$ mole fraction and $\delta^{13} \mathrm{C}-\mathrm{CO}_{2}$ in 2010 and 2012. The slope between the $\mathrm{CO}_{2}$ mole fraction and $\delta^{13} \mathrm{C}-\mathrm{CO}_{2}$ showed -0.050 and $-0.054 \% \mathrm{ppm}^{-1}$, which indicated that the spatial variability of the atmospheric $\mathrm{CO}_{2}$ mole fraction (e.g., a lower mole fraction at NTL than at MLO and CRI) basically occurred due to $\mathrm{CO}_{2}$ exchange between the atmosphere and terrestrial biosphere.

Furthermore, we examined the relationship of the $\mathrm{CO}_{2}$ mole fraction and carbon isotope ratio, because there are some seasonal differences in the species cultivation. On the Indo-Gangetic Plain, rice (especially in Bangladesh) and wheat (especially in northern India), as $\mathrm{C}_{3}$ plants, are cultivated in January-March, while $\mathrm{C}_{4}$ plants, e.g., maize, sugarcane, sorghum, and bajra (pearl millet), in addition to rice are cultivated on the Indo-Gangetic Plain and in Bangladesh in June-September (DAC/MA, 2015; SID/MP, 2018; DES/MAFW, 2019). We calculated the end-member of the isotope value for absorbed $\mathrm{CO}_{2}$ by using intercept values of the Keeling plot between the reciprocal of the $\mathrm{CO}_{2}$ mole fraction and the ratio of $\delta^{13} \mathrm{C}-\mathrm{CO}_{2}$ obtained from two continuous datasets of air samples, which has $>1 \mathrm{ppm}$ difference in $\mathrm{CO}_{2}$ mole fraction and $>0.05 \%$ in $\delta^{13} \mathrm{C}-\mathrm{CO}_{2}$. Since in this study two datasets had 1-week intervals, we assumed that the difference in $\mathrm{CO}_{2}$ and $\delta^{13} \mathrm{C}$ between two datasets would include broader influences of photosynthetic activities from relatively large areas on the Indo-Gangetic Plain.

We found that the intercept values of NTL and CLA showed differences in January-March and June-September
(Fig. 7b), which appeared to reflect the differences in the contributions of $\mathrm{C}_{3}$ and $\mathrm{C}_{4}$ plants in this region. In JuneSeptember, we found relatively heavier intercept values at both NTL $(-25.0 \% \circ \pm 2.4 \%$ ) and CLA $(-23.5 \% \circ \pm 4.1 \%$ ), suggesting that $\mathrm{C}_{4}$ plants partly contributed to the $\mathrm{CO}_{2}$ absorption (or emission) in this season, while in JanuaryMarch, the end-member showed $-29.0 \%$ $\pm 4.3 \%$ (NTL) and $-28.3 \% \circ \pm 4.0 \%$ (CLA), which were similar to the general $\mathrm{C}_{3}$ plant (rice or wheat). If we assume the value for the $\mathrm{C}_{4}$ plant to be $-12 \%$ o to $-14 \%$, the contributions of the $\mathrm{C}_{4}$ plant in NTL and CLA were approximately $25 \% \pm 5 \%$ and $31 \% \pm 9 \%$, respectively. According to the database (DAC/MA, 2015; SID/MP, 2018; DES/MAFW, 2019) for crop area in Uttar Pradesh, the area's ratio of $\mathrm{C}_{4}$ plants (e.g., maize and sugarcane) to $\mathrm{C}_{3}$ plants in the summer season was approximately $26 \%$ in 2012 , which was a similar proportion to that estimated by the $\mathrm{C}$ isotope ratio. In the case of Bangladesh, despite there being no recent data reported, according to data in 2008 , the area for maize was approximately $<10 \%$ compared to the rice area. However, based on the recent $\mathrm{C}$ isotope ratio, it appears likely that more maize has been cultivated.

\section{$3.3 \quad \delta^{18} \mathrm{O}-\mathrm{CO}_{2}$}

In general, $\delta^{18} \mathrm{O}-\mathrm{CO}_{2}$ is related to that value of water in plants and soil, because oxygen atoms of $\mathrm{CO}_{2}$ can be exchanged with oxygen atoms of $\mathrm{H}_{2} \mathrm{O}$ in plant and bacteria cells during photosynthesis and soil respiration. Plants and soil water mainly originate from rainwater in the study region; however, in the case of the agricultural area, water is often introduced by irrigation systems using river water and groundwater. In many cases, photosynthesis produced relatively heavier $\delta^{18} \mathrm{O}-\mathrm{CO}_{2}$ than soil respiration because $\delta^{18} \mathrm{O}$ $\mathrm{H}_{2} \mathrm{O}$ in plants becomes heavier than soil water due to plant transpiration.

Larger amplitudes (approximately 3\%o) in the seasonal variation of $\delta^{18} \mathrm{O}-\mathrm{CO}_{2}$ at both NTL and CLA were observed compared to that of MLO (approximately 0.4\%o) (Fig. 8a). The isotopic ratio of $\delta^{18} \mathrm{O}-\mathrm{CO}_{2}$ at CRI (Bhattacharya et al., 2009) was reported to have similar seasonal variation (i.e., high in winter (November-February) and low in September) to our sites. In the Pacific sites like MLO, $\delta^{18} \mathrm{O}-\mathrm{CO}_{2}$ has a maximum peak from spring to summer, when photosynthesis activity becomes dominant, while a minimum is seen around fall, when the contribution of soil respiration exceeds that of photosynthesis. On the other hand, Indian subcontinent sites seemed to have fairly different seasonal variation patterns, with a maximum in January-February, gradually decreasing from March to September/October and subsequently rapidly increasing (Fig. 8c and d). Such seasonal variation may be influenced by photosynthesis and soil respiration in these regions. However, because many crops are cultivated through the year in these areas (as mentioned in Sect. 3.2), the contribution of photosynthesis to the seasonal variation may be 

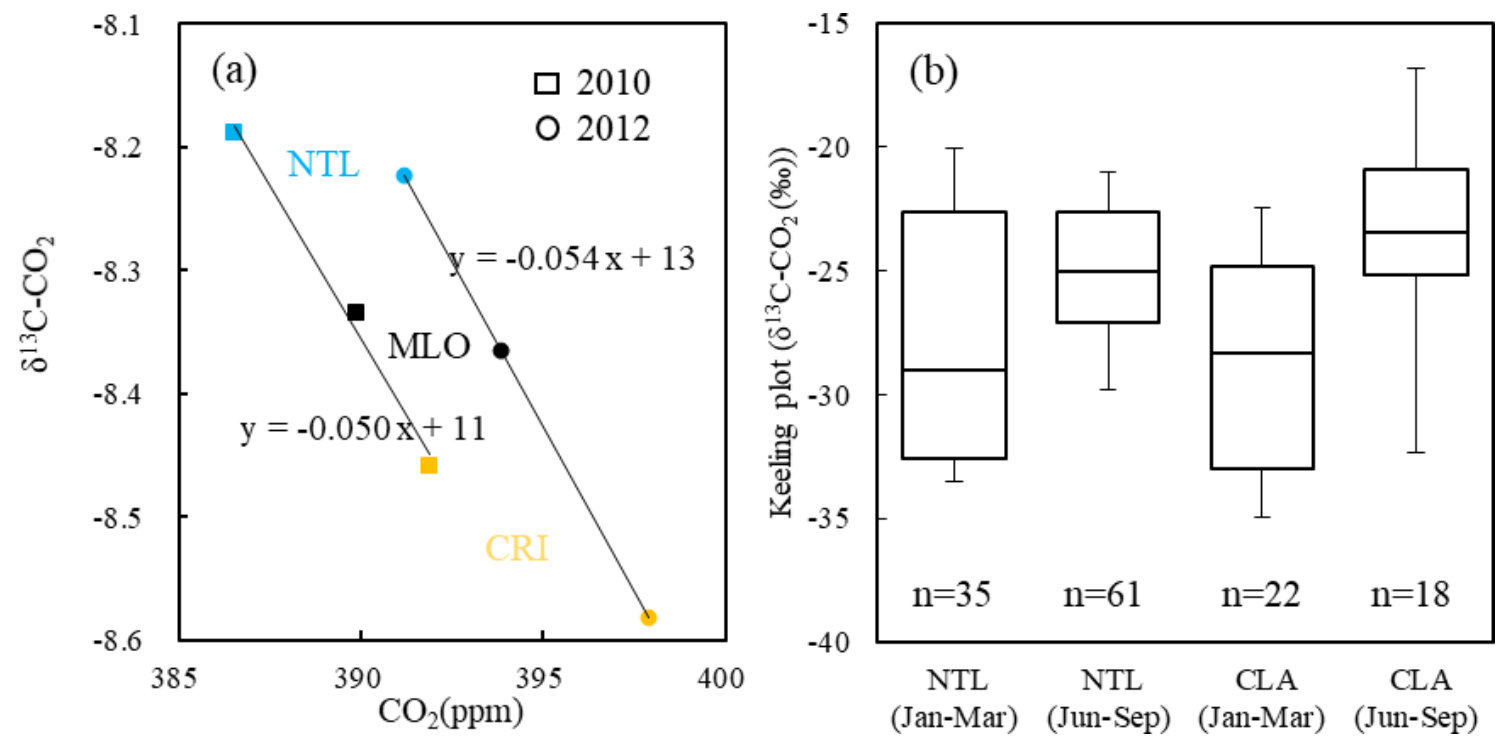

Figure 7. (a) Relationship between the annual values of the $\mathrm{CO}_{2}$ mole fraction and isotopic ratio of $\delta^{13} \mathrm{C}-\mathrm{CO} 2$ at NTL, CRI, and MLO in 2010 and 2012 and (b) the intercept values of the Keeling plot of NTL and CLA in January-March and June-September.

relatively small. High soil respiration activity in the wet season can contribute a little more than during the dry season.

On the other hand, seasonal variations in $\delta^{18} \mathrm{O}$ of rainwater itself seemed to affect $\delta^{18} \mathrm{O}-\mathrm{CO}_{2}$ through photosynthesis and respiration processes. For example, Sengupta and Sarkar (2006) showed that the $\delta^{18} \mathrm{O}-\mathrm{H}_{2} \mathrm{O}$ in rain at New Delhi (western Indo-Gangetic Plain) had a higher value in March-May and a minimum value in September. Such variation was fairly consistent with the seasonal variation in $\delta^{18} \mathrm{O}$ of $\mathrm{CO}_{2}$ at NTL. Similarly, CLA has a minimum $\delta^{18} \mathrm{O}-$ $\mathrm{CO}_{2}$ in the atmosphere in October, which was the same month in which the minimum $\delta^{18} \mathrm{O}-\mathrm{H}_{2} \mathrm{O}$ was observed in rain in eastern Indo-Gangetic Plain areas (e.g., Kolkata near Bangladesh, Sengupta and Sarkar, 2006; Cherrapunij, eastern Indo-Gangetic Plain; Breitenbach et al., 2010). During the rainy season, due to the so-called "amount effect", $\delta^{18} \mathrm{O}$ $\mathrm{H}_{2} \mathrm{O}$ in rain will decrease with an increase in the amount of precipitation (e.g., Rozanski et al., 1993). However, in the Indian region it has been reported that seasonal changes in the origin of moisture strongly affected the $\delta^{18} \mathrm{O}-\mathrm{H}_{2} \mathrm{O}$ (Sengupta and Sarkar, 2006; Tanoue et al., 2018). In winter (i.e., when there is less rain), moisture comes from the west or north. Therefore, the northern area of the Arabian Sea and the western land area supply moisture, which has a higher $\delta^{18} \mathrm{O}$ $\mathrm{H}_{2} \mathrm{O}$. However, the air mass in the summer monsoon season (mainly June-September) comes from the southern part of the Arabian Sea and sometimes passes over the Bay of Bengal, carrying much moisture. The value of $\delta^{18} \mathrm{O}-\mathrm{H}_{2} \mathrm{O}$ in the moisture in the air mass decreases with the process of raining along the air trajectory. In the post-monsoon season (mainly October-December), some portion of moisture comes from the Pacific, Bay of Bengal, and inland area (Tanoue et al., 2018).

In the winter monsoon season (mainly February-May), $\delta^{18} \mathrm{O}-\mathrm{H}_{2} \mathrm{O}$ in rain was reported to be approximately $0 \%$ $1 \%$ (vs. VSMOW). During the winter monsoon season, there is little precipitation, so plant cultivation utilizes irrigation systems using river water and groundwater. River water and groundwater usually show not so large seasonal variation in $\delta^{18} \mathrm{O}$ and have a value close to the annual mean of $\delta^{18} \mathrm{O}-\mathrm{H}_{2} \mathrm{O}$ in rain, such as $-6 \%$ o to $-8 \%$ (Kumar et al., 2019). According to the variation of $\delta^{18} \mathrm{O}-\mathrm{CO}_{2}$, in winter its value was approximately $2 \%$ (vs. VPDB- $\mathrm{CO}_{2}$; the VPDB$\mathrm{CO}_{2}$ scale is fairly close to the scale of $\mathrm{CO}_{2}$ equilibrated with VSMOW, as mentioned in Sect. 2.3), which was higher than that of rain and other water reservoirs, suggesting that $\delta^{18} \mathrm{O}$ $\mathrm{H}_{2} \mathrm{O}$ in plants and soil must become higher due to transpiration during dry and relatively warm conditions in winter.

Based on the fact that, during the summer monsoon season, $\delta^{18} \mathrm{O}-\mathrm{CO}_{2}$ decreased from $1 \%$ to $-2 \%$ with a decrease in $\delta^{18} \mathrm{O}-\mathrm{H}_{2} \mathrm{O}$ from $0 \%$ to $-10 \%$ or $-15 \%$ in the rain, the range of variation in $\delta^{18} \mathrm{O}-\mathrm{CO}_{2}$ was approximately one-third or one-fifth that of rain. Because land water may come from both rain and irrigation systems, the real ranges of $\delta^{18} \mathrm{O}$ in soil water and plant water are likely to be smaller than in the case of rain only. Furthermore, because $\mathrm{CO}_{2}$ from soil respiration contributes more in the rainy season, a balance between photosynthesis and respiration $\mathrm{CO}_{2}$ will, in general, have a small effect on the seasonal variation.

As for the annual trend of $\delta^{18} \mathrm{O}-\mathrm{CO}_{2}$ shown in Fig. 8b, NTL showed a similar pattern to that of MLO, whereas CLA showed a different trend. The $\delta^{18} \mathrm{O}-\mathrm{CO}_{2}$ at NTL began at $0.8 \%$ in 2007 , decreased to $0.2 \%$ in 2011 , and then again 

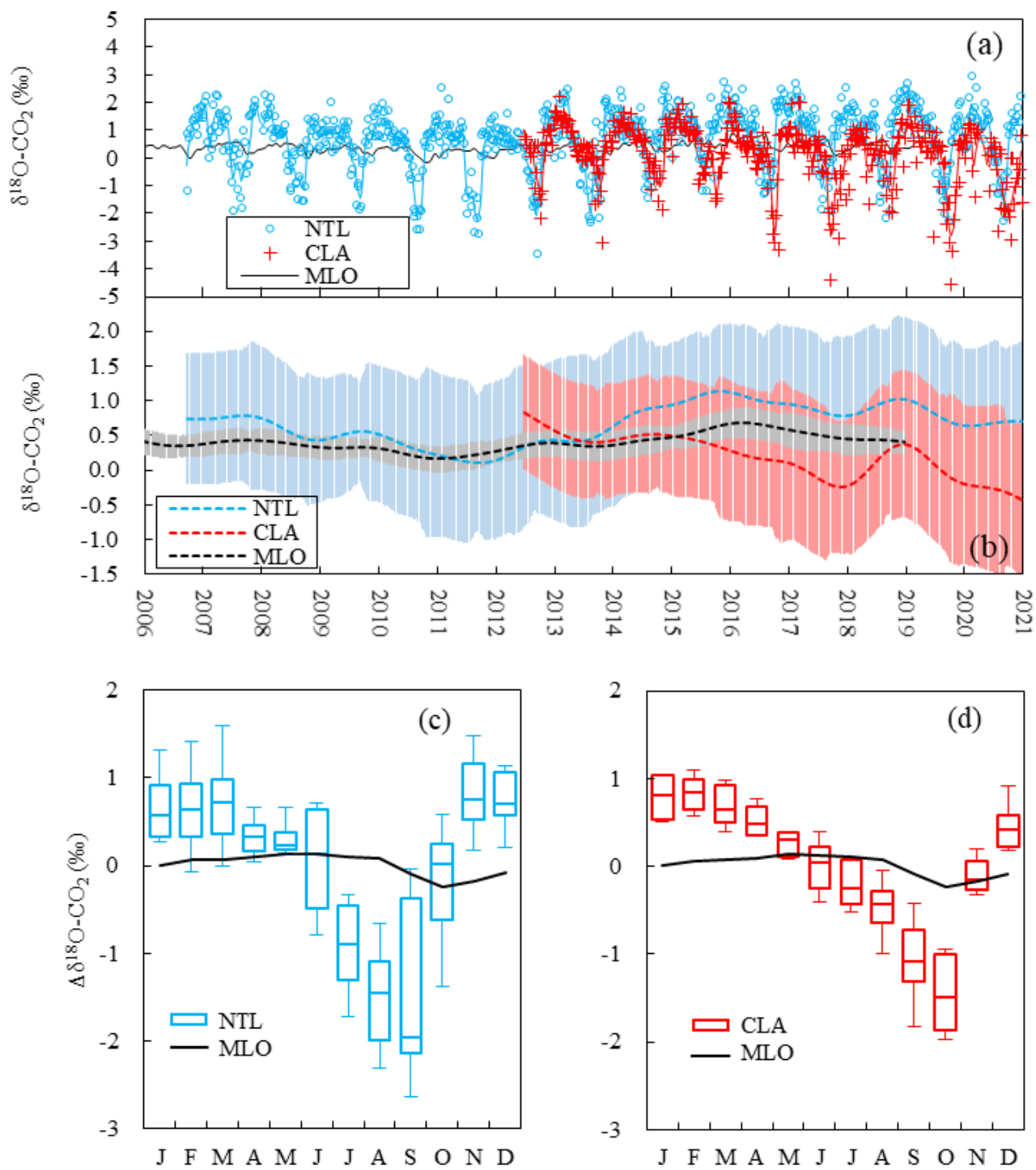

Month
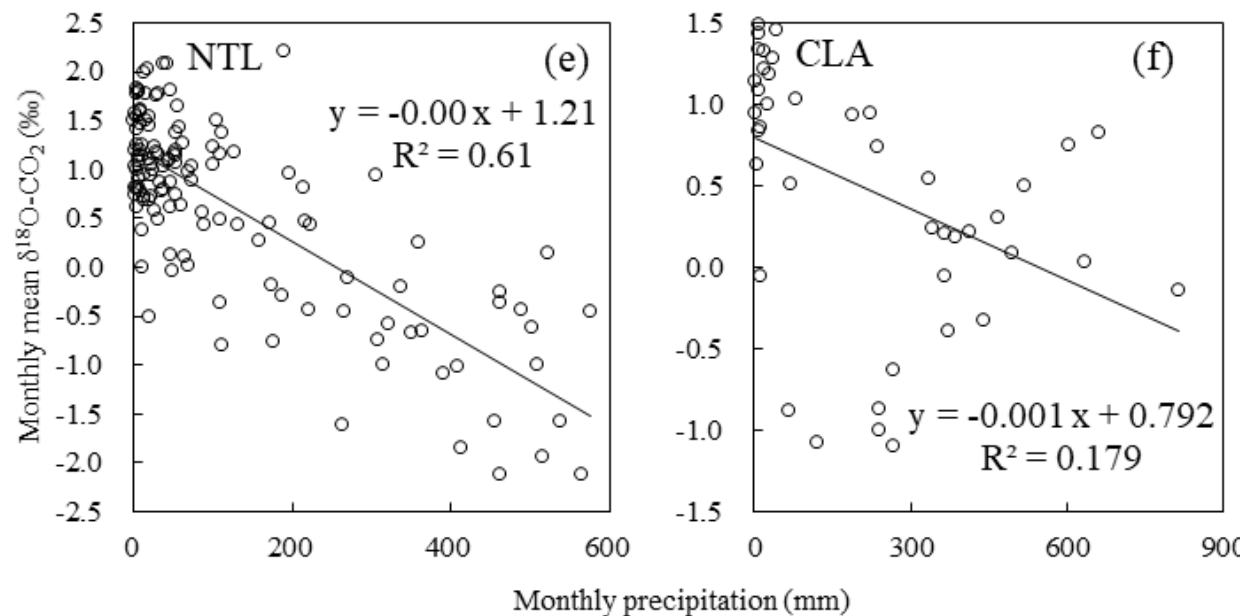

Figure 8. Time series of (a) measured values and (b) the long-term trend for the isotopic ratio of $\delta^{18} \mathrm{O}-\mathrm{CO} 2$ at NTL, CLA, and MLO in 2006-2020, the seasonal variation of $\delta^{18} \mathrm{O}-\mathrm{CO}_{2}$ at (c) NTL and (d) CLA, and the relationship between monthly precipitation of the state of Uttarakhand and Bangladesh and the monthly mean of $\delta^{18} \mathrm{O}-\mathrm{CO}_{2}$ at (e) NTL and (f) CLA. 
became heavier (toward 1.0\%o) during 2014-2016 (Fig. 8b). In northern India, relatively high precipitation was reported during 2011-2013. The tendency of lower $\delta^{18} \mathrm{O}-\mathrm{CO}_{2}$ may have some relationship with the amount of precipitation. In 2008 and 2016 considerable amounts of precipitation fell near NTL. The $\delta^{18} \mathrm{O}-\mathrm{CO}_{2}$ level also seemed to become relatively low. A La Niña event occurred from late 2010 to 2012, and the amount of precipitation increased worldwide from 2010 to 2013. Such large-scale climatic effects are very likely to affect the $\delta^{18} \mathrm{O}-\mathrm{CO}_{2}$ level observed at MLO. In the case of CLA, precipitation increased in 2015-2017 and 2019-2020 (rather than in 2011-2013), and the $\delta^{18} \mathrm{O}-\mathrm{CO}_{2}$ level at CLA seemed to become lower at that time with the increase in precipitation. Analyzing the relationship between the monthly amount of precipitation and $\delta^{18} \mathrm{O}-\mathrm{CO}_{2}$ in Fig. $8 \mathrm{e}$ and $\mathrm{f}$, a weak negative correlation can be seen (if the monthly mean $\delta^{18} \mathrm{O}_{-} \mathrm{CO}_{2}$ at CLA adds 1 or 2 months of time lag to the monthly mean of the precipitation, the correlation coefficient $\left(R^{2}\right)$ between the monthly mean $\delta^{18} \mathrm{O}-\mathrm{CO}_{2}$ at CLA and the monthly mean of precipitation increases to be 0.4 or 0.5 ). Therefore, the amount of precipitation partly contributes to the regional level of $\delta^{18} \mathrm{O}-\mathrm{CO}_{2}$. However, it must be influenced not only by precipitation, but also by seasonal changes in air flow patterns and rain systems, as explained above, as well as by the water reservoir situation, soil water content at that time, and photosynthesis in the region.

If the groundwater storage decreases due to wider usage of irrigation and/or less precipitation in recent times, it causes a stronger transpiration effect in the soil environment, making the $\delta^{18} \mathrm{O}$ of soil water heavier than usual. Roxy et al. (2015) and Asoka et al. (2017) reported that precipitation over the Indian subcontinent and groundwater storage in northern India have had a decreasing trend due to Indian Ocean warming, which is estimated to have occurred due to the weakening trend of the summer monsoon cross-equatorial flow (Swapna et al., 2014). However, much longer records of $\mathrm{CO}_{2}$ isotopic ratios are needed to clarify the increasing trend in $\delta^{18} \mathrm{O}-\mathrm{CO}_{2}$ and the relationship with climatic changes in this region.

\section{$3.4 \mathrm{CH}_{4}$}

The $\mathrm{CH}_{4}$ mole fractions at NTL and CLA are illustrated in Fig. 9a. We detected high $\mathrm{CH}_{4}$ mole fractions at NTL and CLA, where they sometimes exceeded 2100 and $4000 \mathrm{ppb}$, respectively, showing that the Indo-Gangetic Plain region had relatively strong $\mathrm{CH}_{4}$ emissions. The seasonal amplitude of the $\mathrm{CH}_{4}$ mole fraction, especially at CLA $(486 \pm 225 \mathrm{ppb}$; Table 2), was much larger than those of other Indian sites such as NTL (114 ppb), CRI (200 ppb) (Bhattacharya et al., 2009), Darjeeling (400 ppb) (Ganesan et al., 2013), HLE (29 ppb), PON (124 ppb), and PBL (144 ppb) (Lin et al., 2015), which indicated that the contribution of the $\mathrm{CH}_{4}$ source (e.g., rice cultivation) around CLA was relatively strong. Mean seasonal variations in the $\mathrm{CH}_{4}$ mole fraction for both sites were calculated and are shown in Fig. 9c and d. The mole fractions at both NTL and CLA had the highest peak in August-October and a small peak in March. In general, the $\mathrm{CH}_{4}$ mole fraction in the Northern Hemisphere decreased in July-September (summer season) through the decomposition process by reaction with $\mathrm{OH}$ radicals during this period. A higher $\mathrm{CH}_{4}$ mole fraction in this period strongly suggests that there are some sources of $\mathrm{CH}_{4}$. Observation results at Darjeeling (northeastern Indian site; Ganesan et al., 2013), HLE (Lin et al., 2015), and Shadnagar (Sreenivas et al., 2016) also indicated high $\mathrm{CH}_{4}$ mole fractions during August-October. Ganesan et al. (2013) reported that the $\mathrm{CH}_{4}$ mole fraction at Darjeeling was enhanced by transported air masses from the Indo-Gangetic Plain. Lin et al. (2015) and Sreenivas et al. (2016) showed that the high $\mathrm{CH}_{4}$ mole fractions at HLE and Shadnagar were influenced by emissions from paddy fields and wetlands. Garg et al. (2011) showed that $\mathrm{CH}_{4}$ emission from rice fields was estimated to be approximately $17 \%$ of the total $\mathrm{CH}_{4}$ emissions in India. According to the emission database of EDGAR v4.3.2 (ECJRC/PBL, 2016), rice cultivation was the largest source of $\mathrm{CH}_{4}$ (approximately $50 \%$ ) in Bangladesh.

Bhatia et al. (2011) measured the $\mathrm{CH}_{4}$ flux from paddy fields at New Delhi and showed that it was the highest in August-September due to the increase in the activity of rice roots and bacteria in the paddy field soils. Ali et al. (2012) also measured the $\mathrm{CH}_{4}$ flux from paddy fields at Bangladesh and reported that the $\mathrm{CH}_{4}$ flux was maximized within 77$98 \mathrm{~d}$ after the planting of rice due to the increase in root respiration and carbon in soil. It was considered that both March and September-October were consistent with the timing of increasing $\mathrm{CH}_{4}$ production at rice fields according to the customary cultivation schedule of rice in this region. In Bangladesh and the eastern Indian district, rice is cultivated from November to September, as mentioned above in the $\mathrm{CO}_{2}$ section, and $\mathrm{CH}_{4}$ emissions are considered to continue during winter, supporting higher $\mathrm{CH}_{4}$ mole fractions from August to March, especially at CLA.

On the other hand, CRI (Bhattacharya et al., 2009), PON, and PBL (Lin et al., 2015) did not show higher $\mathrm{CH}_{4}$ mole fractions in August-October, as shown in Fig. 9c and d. The air masses at those sites in August-October were transported from the Indian Ocean, which may have only a minimal influence from agricultural emission.

$\mathrm{CH}_{4}$ mole fractions at NTL and CLA were higher than that at MLO, even at the time of year when rice is not cultivated. $\mathrm{CH}_{4}$ emissions from the enteric fermentation and wastewater handling were reported to be large sources according to the emission database in EDGAR v4.3.2 (EC-JRC/PBL, 2016). Garg et al. (2011) reported that enteric fermentation by cattle and buffalo contributes approximately $40 \%$ of emissions in India. Such $\mathrm{CH}_{4}$ emissions must always elevate the $\mathrm{CH}_{4}$ mole fraction in the air mass in these sites regardless of the season. 

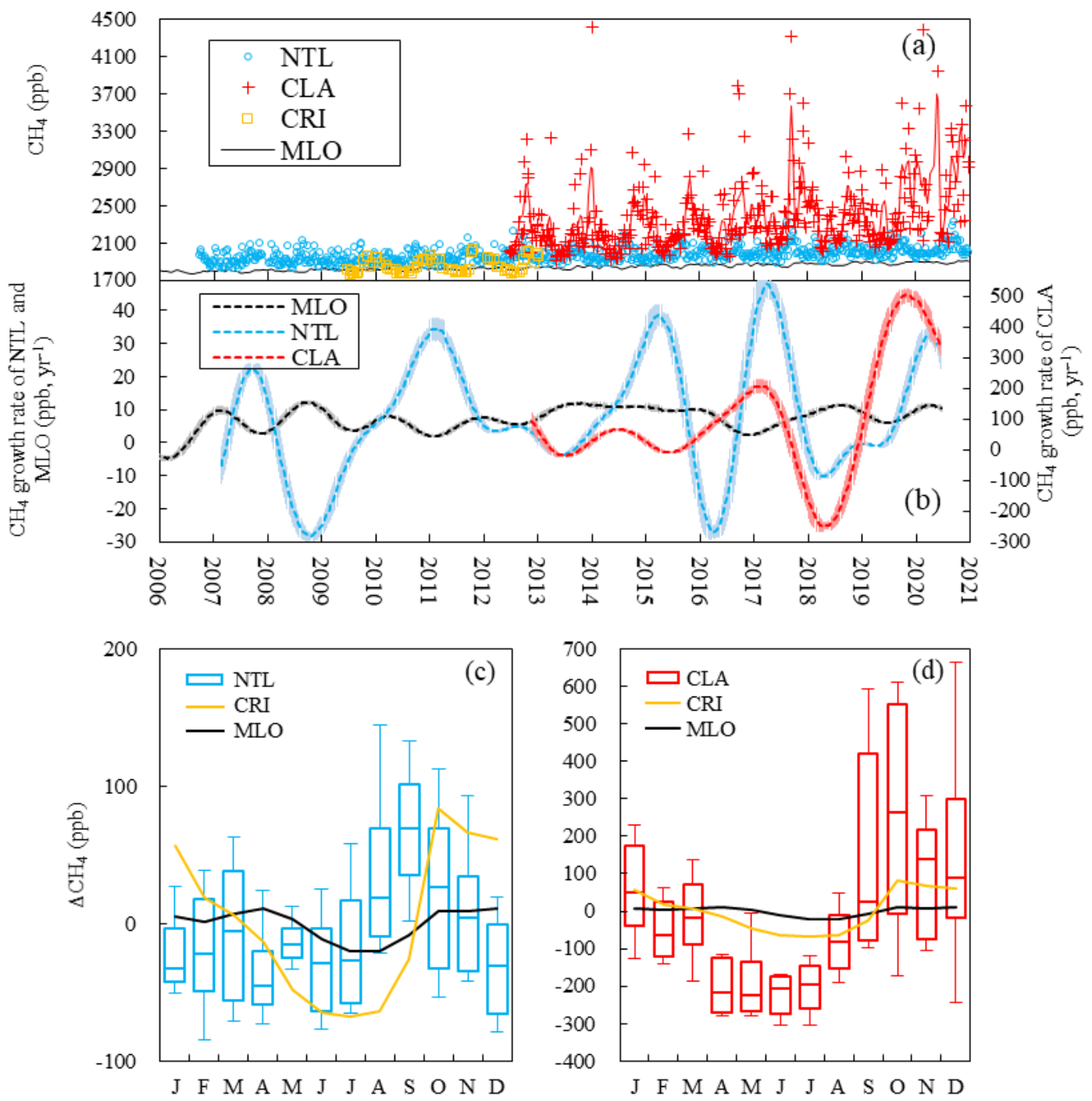

Month
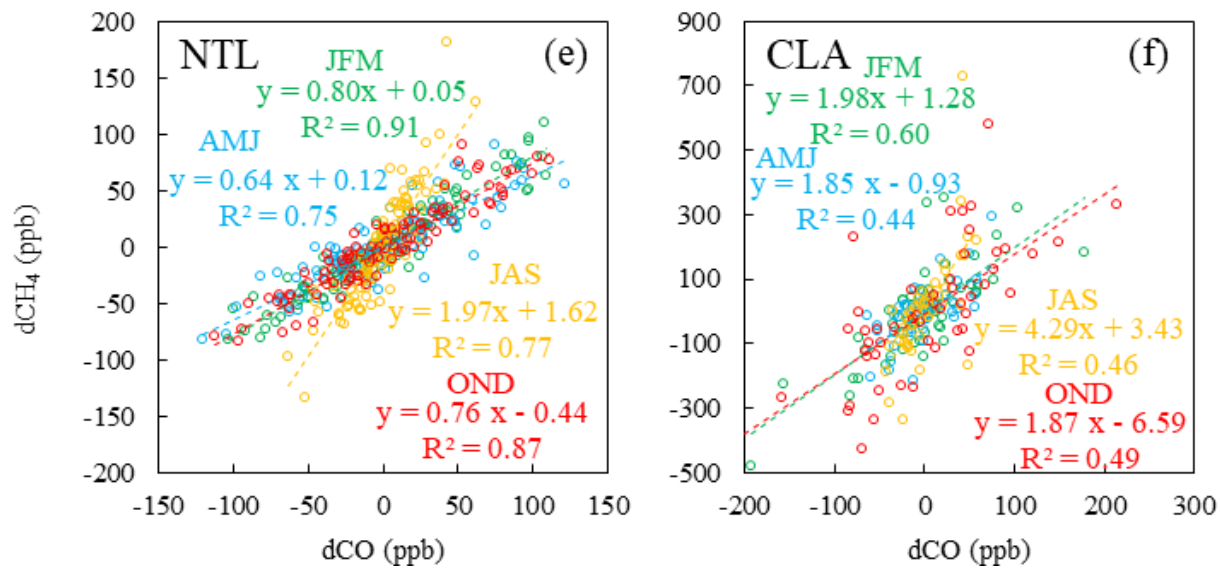

Figure 9. Time series of (a) measured values and (b) growth rates of the $\mathrm{CH}_{4}$ mole fraction at NTL, CLA, CRI, and MLO in 2006-2020, the seasonal variation in the $\mathrm{CH}_{4}$ mole fraction at (c) NTL and (d) CLA, and the relationship between the short-term components of dCO and $\mathrm{dCH}_{4}$ at (e) NTL and (f) CLA during January-March (JFM), April-June (AMJ), July-September (JAS), and October-December (OND). 
In addition, biomass burning (including residential cooking and agricultural residue burning) is very likely to have a contribution to the $\mathrm{CH}_{4}$ mole fraction according to the inventory evaluation (i.e., $21 \%$ contribution; Garg et al., 2011). Reasonably good correlations were seen between short-term components in variations of $\mathrm{CH}_{4}$ and $\mathrm{CO}$ in January-March, April-June, and October-December. Ratios of $\mathrm{dCH}_{4}$ to $\mathrm{dCO}$ showed ranges such as $0.64-0.80 \mathrm{ppb} \mathrm{ppb}^{-1}$ in NTL and $1.85-1.98 \mathrm{ppb} \mathrm{ppb}^{-1}$ in CLA, as shown in Fig. 9e and $\mathrm{f}$. One of the major CO sources in India was considered to be biomass burning (Dickerson et al., 2002). Akagi et al. (2011), EC-JRC/PBL (2016), and Sfez et al. (2017) reported that the emission ratios of $\mathrm{CH}_{4}$ to $\mathrm{CO}$ in biomass burning such as crop residue burning, firewood burning, and biogas burning were $0.04-0.90 \mathrm{ppb} \mathrm{ppb}^{-1}$. Therefore, the ratios observed in these seasons could suggest a strong influence on $\mathrm{CH}_{4}$ and $\mathrm{CO}$ emissions from biomass burning (such as crop residue burning), despite the other large $\mathrm{CH}_{4}$ emissions such as paddy fields and waste treatment, which will increase the ratio, especially at CLA in July-September.

As a result, it is evident that annual $\mathrm{CH}_{4}$ mole fractions at the sites used in this study on the Indo-Gangetic Plain are enriched by various $\mathrm{CH}_{4}$ sources, depending on the season. Generally speaking, because April-June is a dry and hot season, $\mathrm{CH}_{4}$ decomposition processes will proceed, decreasing its mole fraction at both sites.

The variability in the $\mathrm{CH}_{4}$ growth rate in the trend line at NTL was different to the variability at MLO (Fig. 9b), which may be influenced by regional climatic condition, including the Indian Ocean Dipole. Because the frequency of air mass transportation from the south increased if the Indian Ocean Dipole was often activated, the air mass passed over the IndoGangetic Plain (which has strong $\mathrm{CH}_{4}$ emissions), reaching NTL with a high $\mathrm{CH}_{4}$ mole fraction. The difference between the variability in the $\mathrm{CH}_{4}$ growth rate between NTL and CLA may also be explained by the above hypothesis. If the frequency of air mass transportation from the south increased by the activation of the Indian Ocean Dipole (e.g., in 2015) because the air mass was directly transported from the Indian Ocean with a relatively low $\mathrm{CH}_{4}$ mole fraction, the $\mathrm{CH}_{4}$ mole fraction at CLA would become relatively low compared to a usual year (Fig. 9b). On the other hand, as mentioned previously, in 2015-2017, even in the high Indian Ocean Dipole Mode, Bangladesh had relatively high precipitation, which could strengthen $\mathrm{CH}_{4}$ production from rice paddy fields and other aquatic environments. This potential situation matched the high $\mathrm{CH}_{4}$ mole fraction well in summer and the high growth rate at CLA during 2016-2017.

\subsection{CO}

High annual CO mole fractions at both NTL and CLA (Table 1) indicated that the atmosphere over the Indo-Gangetic Plain was influenced by strong $\mathrm{CO}$ emission sources such as burning of harvest residues and residential burning using solid biofuel, which are considered to be the main $\mathrm{CO}$ emission sources in the region (EC-JRC/PBL, 2016). However, of course, $\mathrm{CO}$ originating from car exhaust and industrial activities remains very likely to have made some contributions to the CO mole fraction (EC-JRC/PBL, 2016).

The main crops around NTL are rice and wheat, and the harvesting periods are September-November and AprilMay, respectively (DAC/MA, 2015). Farmers in this area generally burn harvest residues at their farmland after harvest (Lohan et al., 2018). Venkataraman et al. (2006) reported that the amount of burning on the western Indo-Gangetic Plain has two peaks annually, i.e., in May and November. We could observe the same seasonal variation in the $\mathrm{CO}$ mole fraction in the atmosphere at NTL (Fig. 10c). Kumar et al. (2011) also reported that the highest densities in fire spots were seen in spring and autumn on the western Indo-Gangetic Plain. These suggested that $\mathrm{CO}$ emissions from the burning of harvest residues was one of the most important sources on the western Indo-Gangetic Plain in these seasons.

On the other hand, the seasonal variation in $\mathrm{CO}$ mole fraction at CLA exhibited only one peak in October-March (Fig. 10d). Such seasonal variation was also detected at CRI (Bhattacharya et al., 2009), PON, PBL (Lin et al., 2015), and Ahmedabad (Chandra et al., 2016). In Bangladesh, after the end of the monsoon (October-March), harvest residues are burnt and used to make bricks using some kinds of biofuel as a heat source (Guttikunda et al., 2013). Also, dung is burnt for the stove (Venkataraman et al., 2010) during the winter season. In addition, biofuel is used for cooking (Lawrence and Lelieveld, 2010) throughout the year. Those activities could emit large amounts of CO (Streets et al., 2003; Venkataraman et al., 2010; Maithel et al., 2012).

In addition, the seasonal amplitude of the $\mathrm{CO}$ mole fraction (Table 2) at CLA ( $356 \pm 90 \mathrm{ppb})$ at the eastern IndoGangetic Plain site was much larger than that observed at other Indian sites (e.g., CRI - 200 ppb, PON - 78 ppb, PBL $144 \mathrm{ppb}$, and Ahmedabad - $270 \mathrm{ppb}$ ). The highest CO amplitude observed at CLA was consistent with the model estimation of CO emissions, which showed that the eastern IndoGangetic Plain included areas with the highest $\mathrm{CO}$ emissions (Kumar et al., 2013).

On the other hand, the annual mean CO mole fraction at NTL gradually decreased approximately by $50 \mathrm{ppb}$ for 10 years (2006-2015; Fig. 10a). Especially the monthly mean $\mathrm{CO}$ mole fraction in November of each year (i.e., the highest level in the year) at NTL decreased by $120 \mathrm{ppb}$ during that period. This suggests that the amount of harvest residues burnt decreased, the ratio of incomplete combustion in car engines was improved, or the type of fossil fuel for cooking changed from biofuel to natural gas. Such decreasing trends in the $\mathrm{CO}$ mole fraction level were also detected by Pandey et al. (2017), who reported total-column CO levels during 2003-2014 over the Indo-Gangetic Plain. However, the CO mole fraction level at NTL appeared to increase slightly from 2015. Although the reason for the increase is unclear from 

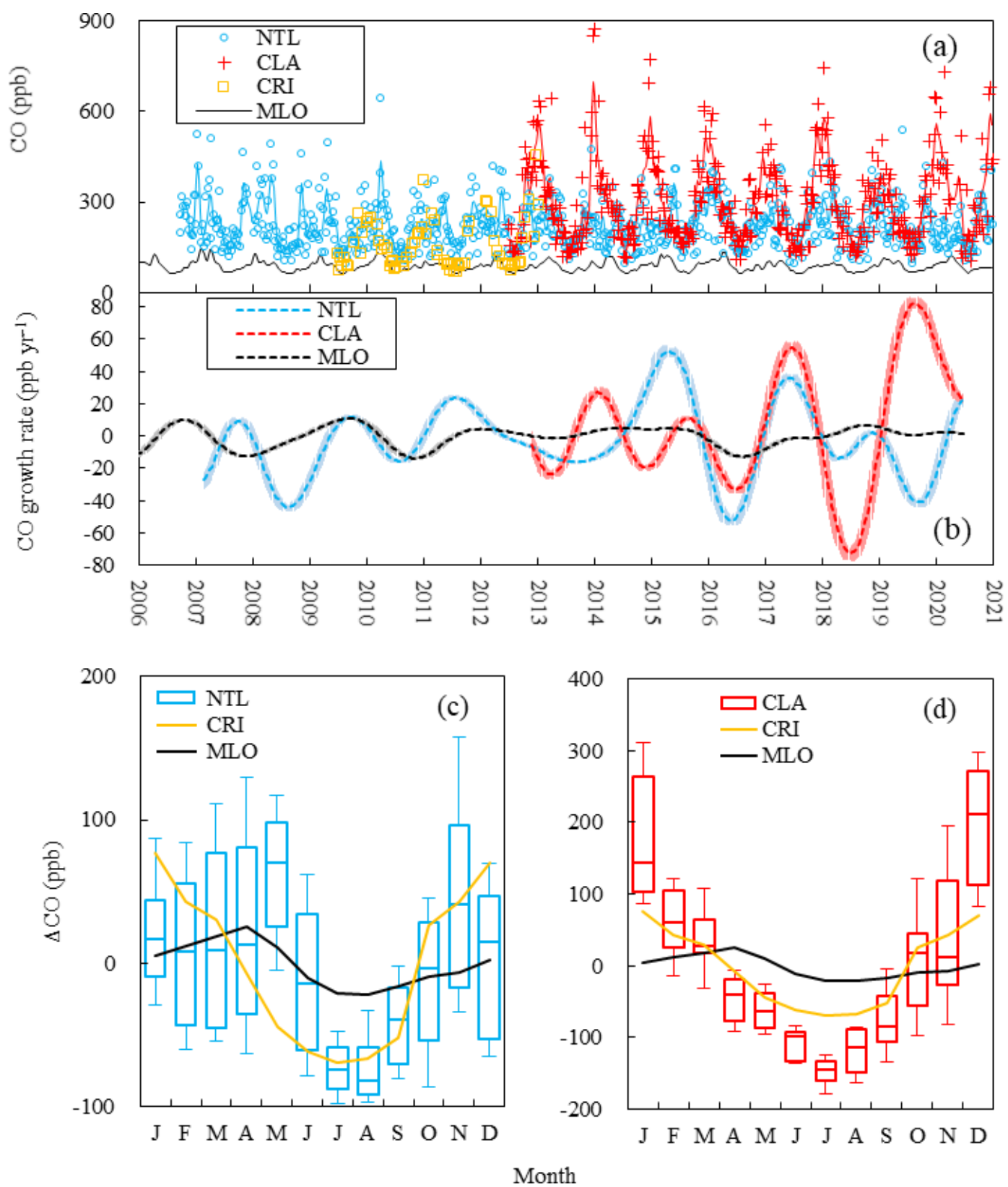

Figure 10. Time series of (a) measured values and (b) growth rates of CO mole fractions at NTL, CLA, CRI, and MLO in 2006-2020 and the seasonal variation of CO mole fractions at (c) NTL and (d) CLA.

this study only, $\mathrm{CO}$ emissions from car exhaust were recently estimated to have increased (EC-JRC/PBL, 2016). Therefore, further monitoring is important.

The trend in the $\mathrm{CO}$ mole fraction and its interannual variability at NTL was similar to those in $\mathrm{CH}_{4}$ at NTL (Figs. 9b and 10b). The mole fractions of $\mathrm{CO}$ and $\mathrm{CH}_{4}$ at NTL tended to be slightly higher when the air mass passed over the IndoGangetic Plain, where there are strong sources of both $\mathrm{CO}$ and $\mathrm{CH}_{4}$. In 2015 and 2017, a large positive Indian Dipole Mode occurred in addition to El Niño in 2015. Therefore, we observed more frequent southern winds, causing higher $\mathrm{CH}_{4}$ and CO mole fractions at NTL. However, at CLA, southern wind will decrease the mole fraction of $\mathrm{CO}$. Thus, temporal variations of both $\mathrm{CO}$ and $\mathrm{CH}_{4}$ mole fractions in both sites must be strongly controlled by meteorological conditions as well as source strength.

\section{6 $\mathrm{H}_{2}$}

Mole fractions, growth rates, and seasonal variations of $\mathrm{H}_{2}$ at both sites are shown in Fig. 11a-d. It was found that CLA, especially, showed a higher mole fraction than the other sites. 
Novelli et al. (1999) reported that the main sources of $\mathrm{H}_{2}$ were combustion (fossil fuel combustion and biomass burning) and photochemical sources such as the oxidation of $\mathrm{CH}_{4}$ and non- $\mathrm{CH}_{4}$ hydrocarbons (NMHCs), which account for $90 \%$ of the total source. The other $10 \%$ is attributed to emissions from volcanoes, oceans, and nitrogen fixation by legumes. Therefore, we have to assume that there are some emission sources at CLA.

On the other hand, $\mathrm{H}_{2}$ is removed from the troposphere by reacting with $\mathrm{OH}$ and by deposition and oxidation at surface soil. The amounts of sources and sinks for $\mathrm{H}_{2}$ in the global budget were estimated to be equal, resulting in a nearequilibrium state (Novelli et al., 1999). The strengths of $\mathrm{H}_{2}$ removal in the atmosphere over the Indian subcontinent do not differ greatly by region according to Yashiro et al. (2011), whereas the strengths of $\mathrm{H}_{2}$ sources may differ by region (Price et al., 2007). Lin et al. (2015) reported that $\mathrm{H}_{2}$ mole fractions at Indian sites were influenced by biomass burning and were $0-40 \mathrm{ppb}$ higher than those at regional background sites (e.g., eastern Kazakhstan and central China). Figure $11 \mathrm{c}$ and $\mathrm{d}$ show the seasonal variations of the $\mathrm{H}_{2}$ mole fraction at NTL and CLA, which illustrate the maximum in May and the minimum in December at NTL and the maximum in November-January and the minimum in JuneAugust at CLA, which were different from the averaged seasonal variation in the Northern Hemisphere, which showed the maximum in March-April and the minimum in AugustSeptember (Novelli et al., 1999).

Because the burning of biomass (such as harvest residuals and dung) appeared to be actively carried out on the IndoGangetic Plain (including at NTL) during April-May and at CLA during November-February, $\mathrm{H}_{2}$ production must, therefore, increase during these seasons. Furthermore, since higher $\mathrm{CH}_{4}$ mole fractions at NTL and CLA were observed during August-September and September-October due to strong paddy field emissions at those times, $\mathrm{H}_{2}$ production from $\mathrm{CH}_{4}$ degradation can also increase. Figure 11e and $\mathrm{f}$ show short-term variable components (such as $\mathrm{dCO}$ and $\mathrm{dH}_{2}$, $\mathrm{dCH}_{4}$, and $\mathrm{dH}_{2}$ ) at both NTL and CLA during those periods and that they had positive correlations. These figures may suggest some relationship between $\mathrm{H}_{2}$ emission with biomass burning and between photochemical reactions between $\mathrm{OH}$ and $\mathrm{CH}_{4}$, respectively. Furthermore, the minimum $\mathrm{H}_{2}$ in June-August was influenced by a fresh air mass from the Indian Ocean which is only minimally affected by anthropogenic emission.

As mentioned above, the $\mathrm{H}_{2}$ mole fraction level at CLA was higher than that at NTL. The amplitude of the seasonal variation of the $\mathrm{H}_{2}$ mole fraction (Table 2) at CLA showed $70.4 \pm 42.2 \mathrm{ppb}$, which was also larger than the amplitudes at other Indian sites such as Nainital (50 ppb), CRI (50 ppb) (Bhattacharya et al., 2009), HLE (22 ppb), PON (16 ppb), and PBL (22 ppb) (Lin et al., 2015). These tendencies were consistent with the results of Price et al. (2007), which indicated a larger $\mathrm{H}_{2}$ emission area around the eastern Indo-
Gangetic Plain, such as at CLA, than in the western Indian subcontinent. Thus, our observation and previous studies both indicated that the Indian subcontinent had relatively strong $\mathrm{H}_{2}$ sources.

\section{$3.7 \quad \mathrm{~N}_{2} \mathrm{O}$}

Garg et al. (2012) reported that the agricultural sector accounted for approximately $75 \%$ of the total $\mathrm{N}_{2} \mathrm{O}$ emission in India in 2005, including around $49 \%$ from nitrogen fertilizer use. In particular, they reported that northern India (the Indo-Gangetic Plain) has the highest $\mathrm{N}_{2} \mathrm{O}$ emission in India because nitrogen fertilizer was applied to extensive paddy fields and was denitrified and that $\mathrm{N}_{2} \mathrm{O}$ was produced and emitted into the atmosphere. Ganesan et al. (2013) reported that the $\mathrm{N}_{2} \mathrm{O}$ mole fraction at Darjeeling (northeastern Indian site) was enhanced due to air mass transportation from the Indo-Gangetic Plain. The annual mean $\mathrm{N}_{2} \mathrm{O}$ mole fraction at NTL (Table 1) appeared to be almost the same as at the Darjeeling sites in northern India and was higher than at another two Indian sites (CRI; Bhattacharya et al., 2009; and HLE; Lin et al., 2015) and at MLO (Fig. 12a).

Thompson et al. (2014) estimated that the $\mathrm{N}_{2} \mathrm{O}$ emissions of the eastern Indo-Gangetic Plain, including CLA, were higher than those of the western Indo-Gangetic Plain. This is supported by our observation results that show that the $\mathrm{N}_{2} \mathrm{O}$ annual mean mole fraction during 2013-2019 at CLA on the eastern Indo-Gangetic Plain was 1-2 ppb higher than at NTL on the western Indo-Gangetic Plain (Table 1), and the seasonal amplitude of the $\mathrm{N}_{2} \mathrm{O}$ mole fraction (Table 2) at CLA $(4.25 \pm 1.45 \mathrm{ppb})$ was higher than the amplitudes at other Indian sites (NTL; CRI, Bhattacharya et al., 2009; HLE; PON; and PBL, Lin et al., 2015). Raut et al. (2011) reported the highest $\mathrm{N}_{2} \mathrm{O}$ emission rates in the regions of Bangladesh and Sri Lanka due to their high usage of urea as a fertilizer.

However, interestingly, PON and PBL, where oceanic air from the Bay of Bengal affected the sites (Lin et al., 2015), seemed to have relatively higher mole fractions than the sites in this study. As for the seasonal variation in the $\mathrm{N}_{2} \mathrm{O}$ mole fraction at NTL, a higher mole fraction was seen in MaySeptember (Fig. 12c). Generally, nitrogen fertilizer was frequently applied to paddy fields in May-September in northern India. Gupta et al. (2016) measured the $\mathrm{N}_{2} \mathrm{O}$ flux in paddy fields at New Delhi and reported that the flux increased immediately after the application of nitrogen fertilizer to the fields. Therefore, high $\mathrm{N}_{2} \mathrm{O}$ levels and increases in the $\mathrm{N}_{2} \mathrm{O}$ mole fraction at NTL in May-September were influenced by the enhancement of the $\mathrm{N}_{2} \mathrm{O}$ flux due to the denitrification of nitrogen fertilizer in paddy fields.

The $\mathrm{N}_{2} \mathrm{O}$ mole fraction at CLA increased in NovemberFebruary (Fig. 12d), and such seasonal variation was almost identical to the seasonal variation in $\mathrm{CO}$ at CLA. The seasonal component in the $\mathrm{N}_{2} \mathrm{O}$ mole fraction $\left(\Delta \mathrm{N}_{2} \mathrm{O}=\right.$ deviation of the $\mathrm{N}_{2} \mathrm{O}$ mole fraction from the long-term trend) at CLA showed positive corre- 

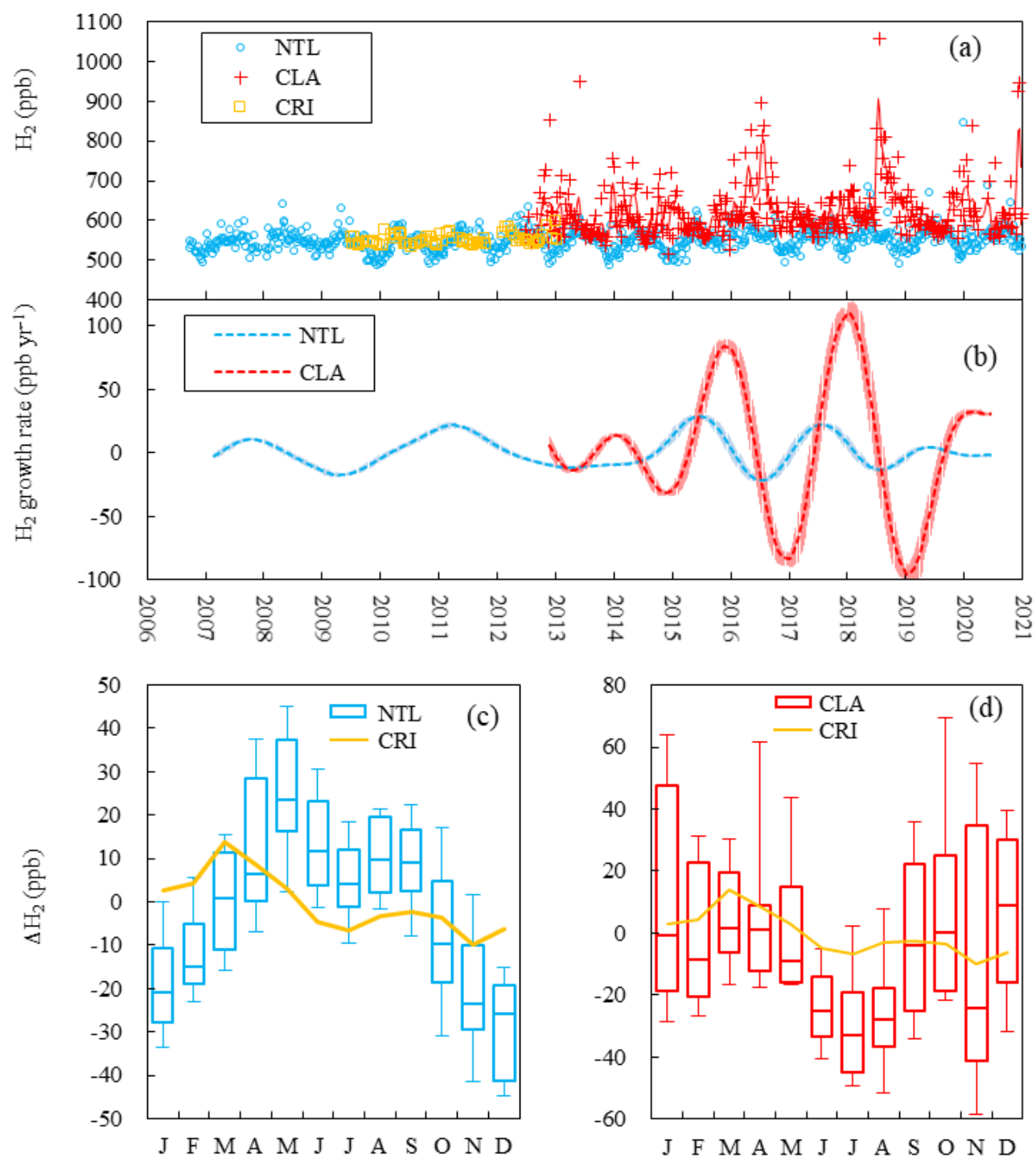

Month
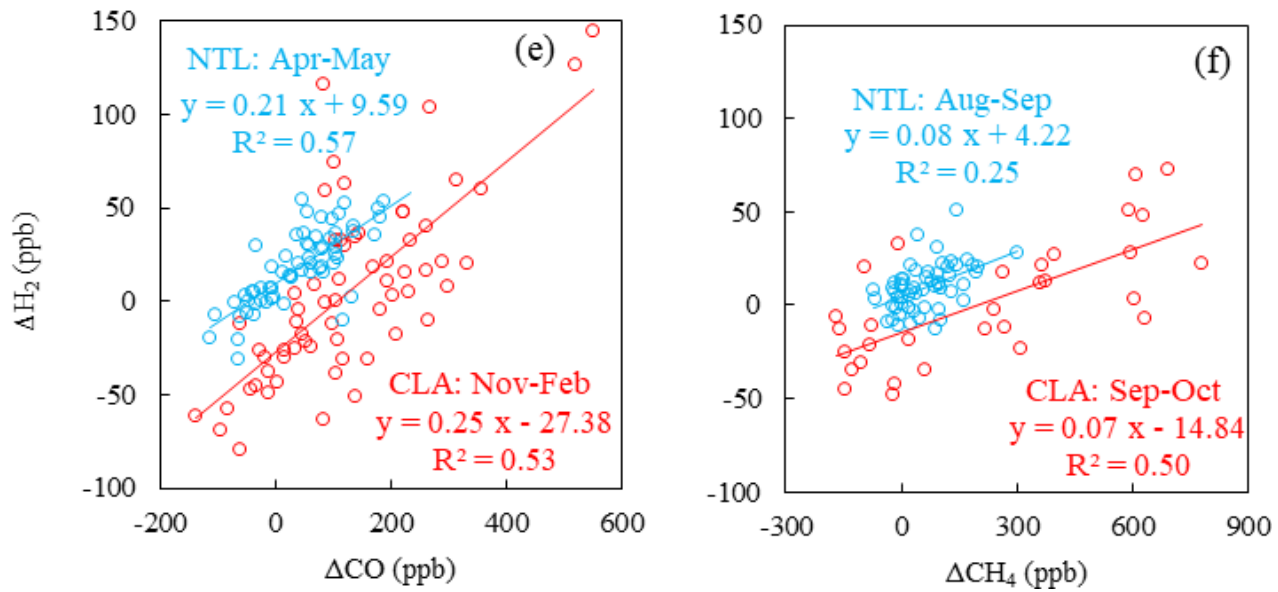

Figure 11. Time series of (a) measured values and (b) growth rate of the atmospheric $\mathrm{H}_{2}$ mole fraction at NTL, CLA, and CRI in 2006-2020 and seasonal variation in the $\mathrm{H}_{2}$ mole fraction at (c) NTL and (d) CLA and scatter plots for the relationship of (e) $\Delta \mathrm{H}_{2}$ and $\Delta$ CO at NTL during April-May and at CLA during November-February when biomass burning occurred frequently, and (f) $\Delta \mathrm{H}_{2}$ and $\Delta \mathrm{CH} 4$ at $\mathrm{NTL}$ during August-September and at CLA during September-October when the maximum $\mathrm{CH}_{4}$ mole fraction was measured. 

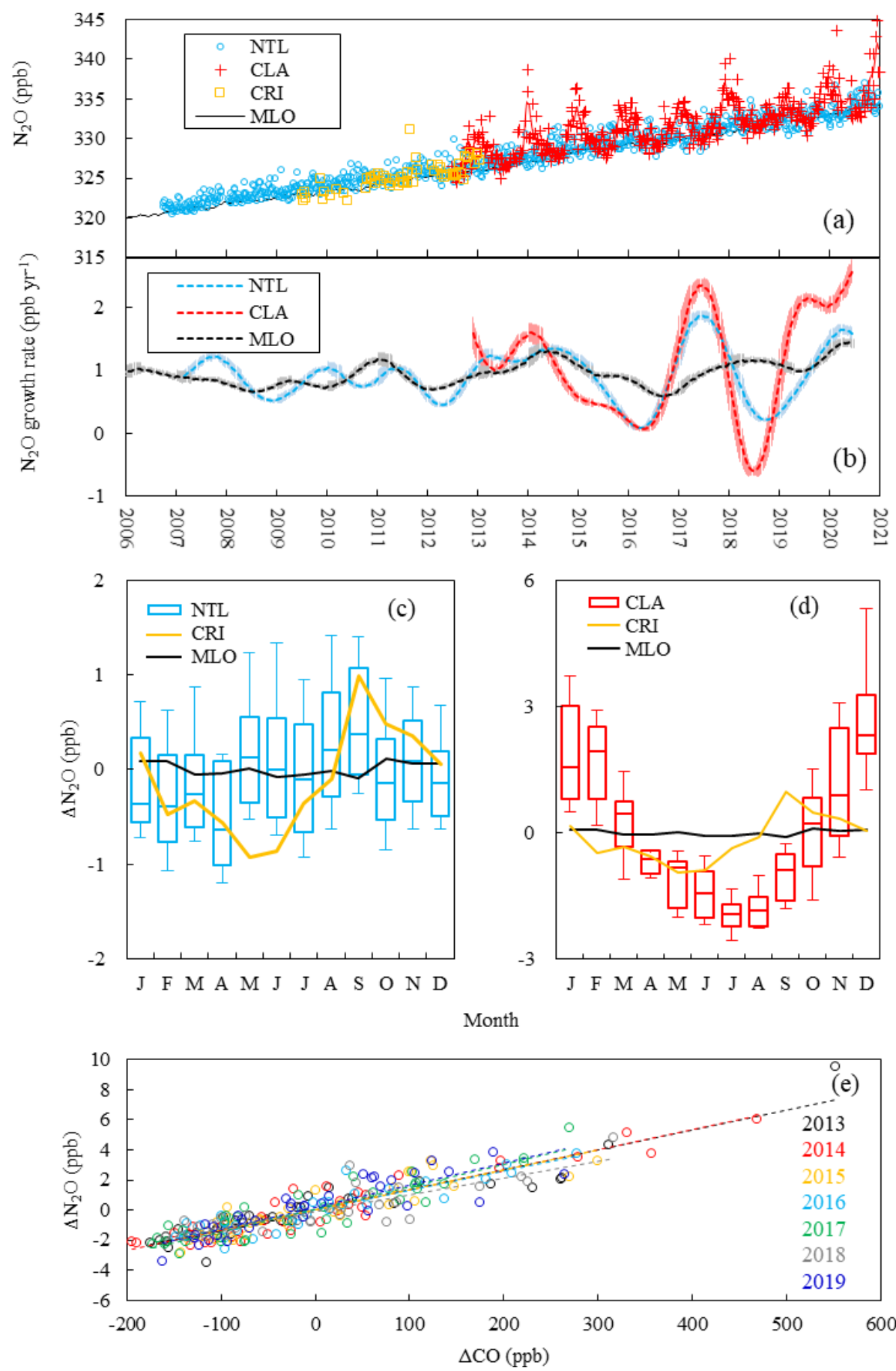

Figure 12. Time series of (a) measured values and (b) growth rates of the $\mathrm{N}_{2} \mathrm{O}$ mole fraction at NTL, CLA, and MLO in 2006-2020, seasonal variations in the $\mathrm{N}_{2} \mathrm{O}$ mole fraction at (c) NTL and (d) CLA, and (e) the relationship between the $\Delta \mathrm{N}_{2} \mathrm{O}$ and $\Delta$ CO at CLA in 2013-2019.

lations $\left(R^{2}=0.81-0.88\right)$ with that of the $\mathrm{CO}$ mole fraction $(\triangle \mathrm{CO})$ each year (Fig. 11e). Also, their ratio $\left(\Delta \mathrm{N}_{2} \mathrm{O} / \Delta \mathrm{CO}\right)$ showed $0.013-0.015 \mathrm{ppb} \mathrm{ppb}^{-1}$, which was the same $\left(0.015 \mathrm{ppb} \mathrm{ppb}^{-1}\right)$ as the ratio of total $\mathrm{N}_{2} \mathrm{O}$ and total $\mathrm{CO}$ emissions in Bangladesh from the EDGAR v4.3.2 database (EC-JRC/PBL, 2016). Although such seasonal vari- ation is likely to be partly related to the lower mixing height in the winter season, variations in $\mathrm{N}_{2} \mathrm{O}$ emission flux must affect the seasonal variations in the mole fraction. In general, the $\mathrm{CO}$ mole fraction was influenced by biomass burning in this season. Because many inventory data showed that biomass burning produced both $\mathrm{N}_{2} \mathrm{O}$ and $\mathrm{CO}, \mathrm{N}_{2} \mathrm{O}$ 
may be affected partly by emission from biomass burning. However, the emission ratios of $\mathrm{N}_{2} \mathrm{O}$ to $\mathrm{CO}$ are fairly variable, with an approximate range of 0.0004-0.017 (Andreae and Merlet, 2001; Sahai et al., 2007, 2011; EDGAR v4.3.2, EC-JRC/PBL, 2016). It seemed that this ratio changes with the types of plants that are burnt. According to Sahai et al. (2011), because the ratio was approximately 0.004 in the case of rice straw, some portion (e.g., 0.004/0.015, i.e., approximately $27 \%$ at the most) of $\mathrm{N}_{2} \mathrm{O}$ in the atmosphere may originate from biomass burning. In addition, since Venkataraman et al. (2010) reported that dung burning is one of major $\mathrm{N}_{2} \mathrm{O}$ sources among many kinds of biomass burning in India, its contribution was also possible.

On the other hand, nitrification and denitrification processes of nitrogen fertilizer in rice paddy soil are considered to be major causes of $\mathrm{N}_{2} \mathrm{O}$ emissions in this region (EDGAR v4.3.2); however, the emission rate appeared to have seasonal variation. Related to the irrigation system, the $\mathrm{N}_{2} \mathrm{O}$ flux was thought to be larger in alternating wet and dry conditions than under continuously flooded conditions (Akiyama et al., 2005; Gaihre et al., 2018; Begum et al., 2019). In the summer monsoon season, many rice paddy fields in Bangladesh must have enough water level because of the ample amount of precipitation. After the summer monsoon (from October), the water level in the paddy field intermittently changed with the situation. Therefore, relatively, a higher $\mathrm{N}_{2} \mathrm{O}$ emission rate likely occurred during the winter season, when rice (boro rice) was still grown, enhancing the $\mathrm{N}_{2} \mathrm{O}$ mole fraction in the winter season. Further observations of high-frequency variations of both $\mathrm{N}_{2} \mathrm{O}$ and $\mathrm{CO}$ mole fractions will contribute towards precisely evaluating the $\mathrm{N}_{2} \mathrm{O}$ emission sources at this site.

The $\mathrm{N}_{2} \mathrm{O}$ growth rates at NTL and CLA were similar to that of MLO (Fig. 12b); however, the variations in the $\mathrm{N}_{2} \mathrm{O}$ growth rate at both NTL and CLA were larger than that of MLO during 2016-2020. The variation in the $\mathrm{N}_{2} \mathrm{O}$ growth rate showed a similar pattern to the growth rates of $\mathrm{CO}$ and $\mathrm{H}_{2}$ (Figs. $9 \mathrm{~b}$ and 10b), indicating that the sources of these gases had basically common characteristics.

\section{8 $\mathrm{SF}_{6}$}

$\mathrm{SF}_{6}$ is mainly emitted artificially from factories and urban areas (Olivier et al., 2005). Ganesan et al. (2013) reported that the $\mathrm{SF}_{6}$ emission at Darjeeling (northeastern Indian site) was considerably weak. Our results also showed that $\mathrm{SF}_{6}$ mole fractions at NTL and CLA were almost the same as the background $\mathrm{SF}_{6}$ mole fraction (e.g., MLO in Fig. 13a and other sites such as HLE, PON, and PBL, Lin et al., 2015). In addition, the annual amplitudes of the $\mathrm{SF}_{6}$ mole fraction at Indian sites (HLE, PON, and PBL) were $0.15,0.24$, and $0.48 \mathrm{ppt}$, respectively, which were almost within the same range (0.15-0.23 ppt) as at NTL and CLA (Table 2). These results suggested that there was no large $\mathrm{SF}_{6}$ source on the Indo-Gangetic Plain.
Figure $13 \mathrm{c}$ and $\mathrm{d}$ show that the seasonal variations of the $\mathrm{SF}_{6}$ mole fraction at NTL and CLA decreased in summer (NTL: July, CLA: June-August), which was the same variation as those detected at PON and PBL (Lin et al., 2015). In the summer season, air masses from the south via the Indian Ocean prevailed in the NTL and CLA regions, as shown in Fig. 2. Generally, the $\mathrm{SF}_{6}$ mole fraction in the Southern Hemisphere was lower than that in the Northern Hemisphere (Geller et al., 1997). Thus, the seasonal variation in the $\mathrm{SF}_{6}$ mole fraction was explained by the frequency of air mass transportation from the south.

Figure $13 \mathrm{~b}$ shows the interannual variability of the $\mathrm{SF}_{6}$ growth rate at NTL, CLA, and MLO and southern air mass contribution at NTL and CLA. The variability in the $\mathrm{SF}_{6}$ growth rate at NTL was different to the variability at MLO, and in fact we could see an anticorrelation between them. In the case of CLA, an anticorrelation was not so clear because of a relatively shorter data record. The decrease in the growth rate at NTL seemed to have a relationship with the increase in the frequency of southern air mass transportation. This indicated that the growth rate of the $\mathrm{SF}_{6}$ mole fraction at NTL may be controlled by the regional climatic condition though the transportation process. Because $\mathrm{SF}_{6}$ had weaker sources in northern India, the variation in its trend could be explained more clearly by the influence of the air mass movements.

As mentioned above, anticorrelation in the growth rates between MLO and this region was also seen in $\mathrm{CO}_{2}$ and $\mathrm{CH}_{4}$. Therefore, we must take into consideration the influence of the variation in large-scale atmospheric circulation on the GHG mole fraction and trends in their growth rates in the Indian region.

\section{Conclusions}

We characterized GHGs and related gases over the northern Indian region using air samples collected weekly at Nainital, India (NTL), and Comilla, Bangladesh (CLA), since 2006 and 2012, respectively. Observation data at both NTL and CLA were compared with the GHG data of other Indian sites and Mauna Loa, Hawaii (MLO), at the Pacific station. From this comprehensive analysis, it was found that the features of seasonal and long-term variations in each gas were influenced by the local sinks and sources during each season and annual climatic conditions on the Indo-Gangetic Plain. They were considerably different to those of the MLO in the Pacific region.

On the Indo-Gangetic Plain, rice, wheat, other cereals, and millet are cultivated in the respective seasons corresponding to the change between wet and dry climatic conditions. Therefore, seasonal variations in the atmospheric $\mathrm{CO}_{2}$ mole fraction were strongly influenced by the crop $\mathrm{CO}_{2}$ sink at that time. In general, low $\mathrm{CO}_{2}$ mole fractions in the winter season in the Northern Hemisphere were not observed; however, we observed relatively lower mole fractions during January- 

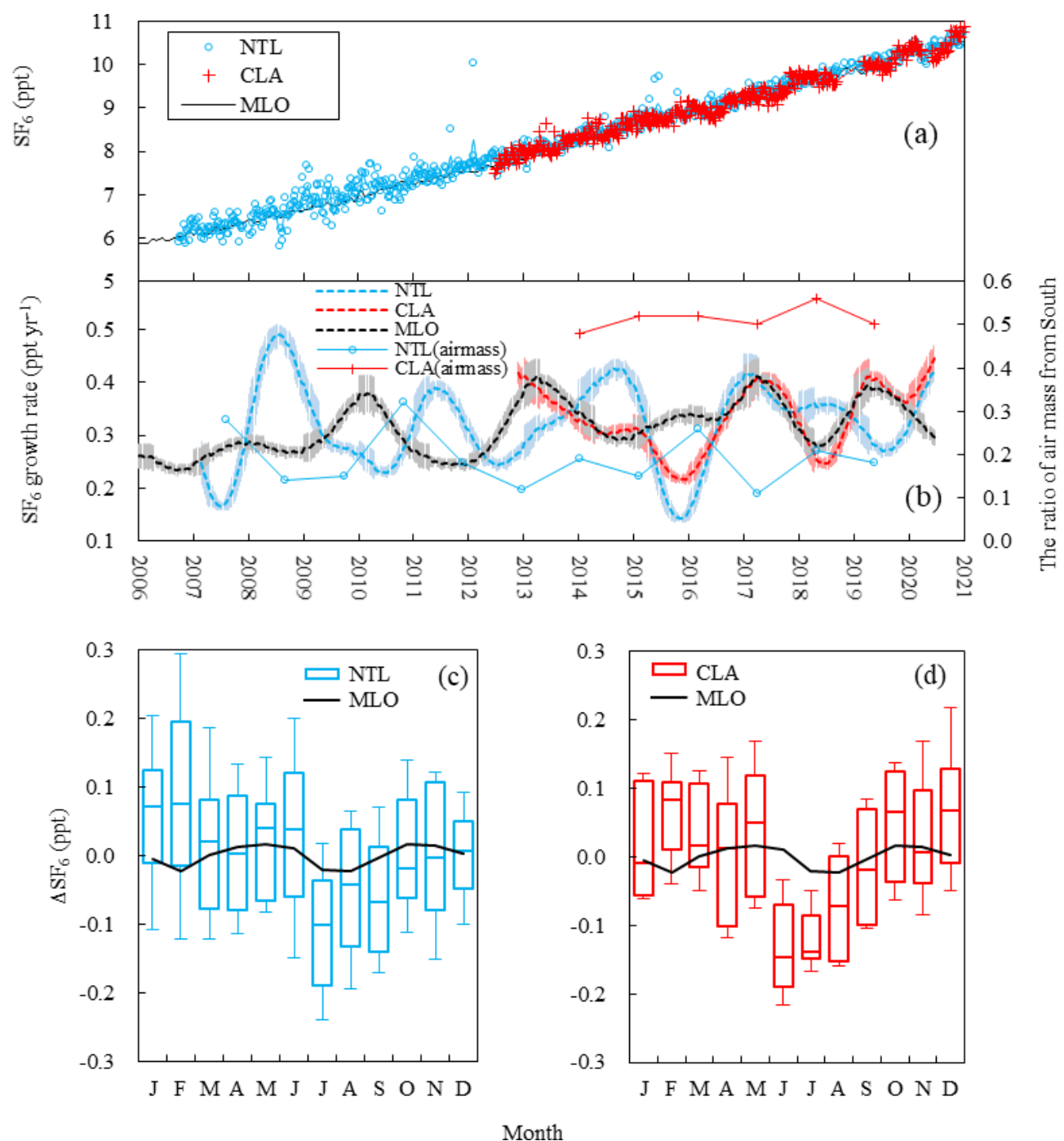

Figure 13. Time series of (a) measured values and (b) growth rates of the $\mathrm{SF}_{6}$ mole fraction at NTL, CLA, and MLO and the ratios of the air mass from the south at NTL and CLA in 2006-2020 and seasonal variations in the SF6 mole fraction at (c) NTL and (d) CLA.

March in this region, especially at CLA. In Bangladesh, rice is grown even in the winter season. The $\delta^{13} \mathrm{C}_{-} \mathrm{CO}_{2}$ signature showed that $\mathrm{C}_{3}$ plants (e.g., rice and wheat) affected the $\mathrm{CO}_{2}$ mole fractions in the winter season, while in the summer season the $\delta^{13} \mathrm{C}-\mathrm{CO}_{2}$ signature showed that $\mathrm{C}_{4}$ plants (corn, sugarcane, etc.) contributed some portion.

The seasonal variations in $\delta^{18} \mathrm{O}-\mathrm{CO}_{2}$ showed almost the same variation as that in the $\delta^{18} \mathrm{O}$ in local rain. Effects of the amount of precipitation and the origin of moisture appeared to affect $\delta^{18} \mathrm{O}$ in local rain and $\mathrm{CO}_{2}$. As a result, $\delta^{18} \mathrm{O}$ in $\mathrm{CO}_{2}$ was affected by the climatic variation related to the amount of precipitation, which was enhanced during 2015-2017. These facts are also consistent with the explanation that $\mathrm{CO}_{2}$ exchange by photosynthesis (and respiration) by land biomass strongly affected $\mathrm{CO}_{2}$ seasonality in the mole fraction.

At both sites, higher $\mathrm{CH}_{4}$ mole fractions were observed than were recorded at other Indian sites. In particular, higher mole fractions than $4000 \mathrm{ppb}$ were recorded at CLA, where rice paddy fields covered the area. Rice cultivation was one of major emission sources in this region. Because $\mathrm{CH}_{4}$ production activities increased after rice planting, we observed the highest peak in September-October at both sites and a small peak in spring at CLA. A large amount of precipitation during those seasons is likely to have affected the $\mathrm{CH}_{4}$ production rate of rice paddy fields through soil anaerobic conditions and, as a result, increased the atmospheric $\mathrm{CH}_{4}$ mole fraction. Air mass transport also influenced seasonal variation and the variability of its growth rate. Besides emissions from rice paddy fields, we identified the relationship between biomass burning and the $\mathrm{CH}_{4}$ mole fraction in a season other than September-October, when biomass burning occurred frequently. In addition, enteric fermentation and wastewater handling were large emission sources in this re- 
gion. The large number of sources appeared to increase the average $\mathrm{CH}_{4}$ mole fraction in this region.

$\mathrm{CO}$ was strongly related to biomass burning activities at both sites. The mole fraction was high in the dry season and after crop harvesting. At CLA in winter, a higher mole fraction was observed together with a high $\mathrm{N}_{2} \mathrm{O}$ mole fraction, which may suggest some link to biomass burning as a $\mathrm{N}_{2} \mathrm{O}$ source. The $\mathrm{CO}$ level gradually decreased throughout the observed period. $\mathrm{CO}$ emissions must, therefore, be reduced by various technical progresses, including automobile emission and industrial combustion efficiency improvements.

We observed higher $\mathrm{N}_{2} \mathrm{O}$ levels in the crop season (i.e., the rainy season) from May to September at NTL but much higher levels in the winter season at CLA. $\mathrm{N}_{2} \mathrm{O}$ is known to be mainly emitted from soil though nitrogen fertilizer applications to rice fields and croplands in this region. However, for CLA, we estimated seasonal variations in the emission rate due to the water level in the rice paddy field, because intermittent irrigation in winter generally produces more $\mathrm{N}_{2} \mathrm{O}$ than continuously flooded conditions in the rainy season.

$\mathrm{H}_{2}$ showed the some relationship with both $\mathrm{CO}$ and $\mathrm{CH}_{4}$ mole fractions. We found that $\mathrm{CO}$ had a good correlation with $\mathrm{H}_{2}$ in the biomass burning season, indicating some $\mathrm{H}_{2}$ contribution from biomass burning. On the other hand, in the season when the $\mathrm{CH}_{4}$ mole fraction was high, the $\mathrm{H}_{2}$ mole fraction was also relatively high compared to $\mathrm{CH}_{4}$, suggesting that chemical reactions of $\mathrm{CH}_{4}$ and $\mathrm{H}_{2}$ may contribute some portion of the $\mathrm{H}_{2}$ mole fraction.

$\mathrm{SF}_{6}$ showed consistent mole fractions with other Indian sites. Seasonal variations were strongly related to the southern air mass frequency, because the $\mathrm{SF}_{6}$ mole fraction in the southern region was relatively low.

We found that the interannual variabilities in $\mathrm{CH}_{4}, \mathrm{SF}_{6}$, and also partly $\mathrm{CO}_{2}$ growth rates at NTL were anticorrelated with those at MLO, which is located in the Pacific. Growth rates for many GHGs are known to be influenced by El Niño events for many reasons (e.g., hot climate, dry conditions on a global scale). However, in the Indian region, growth rates of some GHGs seemed to be more affected by the regional climate condition such as the Indian Ocean Dipole, which usually affects air circulation and precipitation in the Indian region. In the case of CLA, although the data duration was insufficiently short, growth rates of $\mathrm{CO}_{2}, \mathrm{CH}_{4}$, and $\mathrm{SF}_{6}$ changed differently from those at MLO, which could be partly explained by the climatic variations due to the Indian Ocean Dipole. Because CLA is located relatively close to the ocean, sometimes the variation was thought to be different from that at NTL.

These findings have not been reported previously. In this study, long-term records of GHG data at NTL enabled a longterm analysis. These findings suggested that the mole fractions of GHGs and their emissions on the Indian subcontinent could change with climatic conditions in this region in the near future, in addition to changes in anthropogenic activities relating to GHG emissions and countermeasures for the emissions. Therefore, long-term GHG monitoring should be continued, and the effectiveness of countermeasures for reducing GHG emissions on the Indian subcontinent, including the Indo-Gangetic Plain, should be evaluated.

Data availability. Weekly flask sampling data from Nainital and Comilla are available on the NIES website (https://db.cger.nies.go. jp/portal/geds/atmosphericAndOceanicMonitoring?lang=eng, Nomura et al., 2021) by 2021.

Author contributions. SN conducted the data analysis and led the writing of the manuscript. MKA and MN managed the flask sampling of the stations in Comilla and Nainital and provided knowledge about keeping the flask sampling in India and Bangladesh in the long term. YT and HM supervised the study, designed the observation program, and directed the writing of the manuscript. MS and TM managed the measurement of the mole fraction of the flask bottle. PKP supported Comilla measurements. All authors provided feedback on the manuscript.

Competing interests. The authors declare that they have no conflict of interest.

Disclaimer. Publisher's note: Copernicus Publications remains neutral with regard to jurisdictional claims in published maps and institutional affiliations.

Acknowledgements. We would like to thank Deepak Singh Chausali and other staff of the Aryabhatta Research Institute of Observational Sciences (ARIES), and Abu Hena Muhammad Yousuf, Goutam Kumar Kundu, M. Habibullah-Al-Mamun, Kazi Nazrul Islam of University of Dhaka for the assistance rendered during sample collection. Also, we would like to thank the staff of Comilla weather station in Bangladesh Meteorological Department (BMD) and the director of BMD for their great support in this project. We thank Sachiko Hayashida and Naoko Saito for funding support, and Masako Wallwork for technical support. We thank Pieter Tans, Ed Dlugokencky, Paul C. Novelli Geoff. Dutton, Bradley Hall and the Earth System Research Laboratory team of the National Oceanic and Atmospheric Administration (NOAA), and James White, Bruce Vaughn and Sylvia Michel and the Institute of Arctic and Alpine Research team of the University of Colorado for providing the data of Mauna Loa Observatory.

Financial support. This research has been supported by the Environment Research and Technology Development Fund (grant nos. JPMEERF20152002, JPMEERF20182002 and JPMEERF21S20800) of the Ministry of the Environment, Japan, the Environmental Restoration and Conservation Agency of Japan, establishment and running of the air sampling program were partly supported by the Asia Pacific Network (grant no. ARCP2011-11NMY-Patra/Canadell), and the Indian Space Re- 
search Organization-Atmospheric Trace Gases Chemistry, Transport and Modelling (ISRO-ATCTM).

Review statement. This paper was edited by Ronald Cohen and reviewed by five anonymous referees.

\section{References}

Akagi, S. K., Yokelson, R. J., Wiedinmyer, C., Alvarado, M. J., Reid, J. S., Karl, T., Crounse, J. D., and Wennberg, P. O.: Emission factors for open and domestic biomass burning for use in atmospheric models, Atmos. Chem. Phys., 11, 4039-4072, https://doi.org/10.5194/acp-11-4039-2011, 2011.

Akiyama, H., Yagi, K., and Yan, X.: Direct $\mathrm{N}_{2} \mathrm{O}$ emissions from rice paddy fields: summary of available data, Glob. Biogeochem. Cycles, 19, 1-10, 2005.

Ali, M. A., Farouque, M. G., Haque, M., and Ul Kabir, A.: Influence of soil amendments on mitigating methane emissions and sustaining rice productivity in paddy soil ecosystems of Bangladesh, J. Environ. Sci. Nat. Resour., 5, 179-185, 2012.

Andreae, M. O. and Merlet, P.: Emission of trace gases and aerosols from biomass burning, Global Biogeochem. Cycles, 15, 955966, 2001.

Arino, O., Perez, R. J., Julio, J., Kalogirou, V., Bontemps S., Defourny, P., and Van Bogaert, E.: Global land cover map for 2009, GlobCover 2009, European Space Agency (ESA) \& Université catholique de Louvain (UCL), available at: http://www. esa-landcover-cci.org (last access: 6 April 2021), 2012.

Ashok, K., Guan, Z., Saji, N. H., and Yamagata, T.: Individual and combined influences of ENSO and the Indian Ocean dipole on the Indian summer monsoon, J. Clim., 17, 3141-3155, 2004.

Asoka, A., Gleeson, T., Wada, Y., and Mishra, V.: Relative contribution of monsoon precipitation and pumping to changes in groundwater storage in India, Nat. Geosci., 10, 109-117, 2017.

Begum, K., Kuhnert, M., Yeluripati, J. B., Ogle, S. M., Parton, W. J., Williams, S. A., Pan, G., Cheng, K., Ali, M. A., and Smith, P.: Modelling greenhouse gas emissions and mitigation potentials in fertilized paddy rice fields in Bangladesh, Geoderma, 341, 206215, 2019.

Bhatia, A., Ghosh, A., Kumar, V., Tomer, R., Singh, S. D., and Pathak, H.: Effect of elevated tropospheric ozone on methane and nitrous oxide emission from rice soil in north India, Agric. Ecosyst. Environ., 144, 21-28, 2011.

Bhattacharya, S. K., Borole, D. V., Francey, R. J., Allison, C. E., Steele, L. P., Krummel, P., Langenfelds, R., Masarie, K. A., Tiwari, Y. K., and Patra, P. K.: Trace gases and $\mathrm{CO}_{2}$ isotope records from Cabo de Rama, India, Curr. Sci., 97, 1336-1344, 2009.

Brand, W. A., Assonov, S. S., and Coplen, T. B.: Correction for the ${ }^{17} \mathrm{O}$ interference in $\delta\left({ }^{13} \mathrm{C}\right)$ measurements when analyzing $\mathrm{CO}_{2}$ with stable isotope mass spectrometry (IUPAC Technical Report), Pure Appl. Chem., 82, 1719-1733, 2010.

Breitenbach, S. F. M., Adkins, J. F., Meyer, H., Marwan, N., Kumar, K. K., and Haug, G. H.: Strong influence of water vapor source dynamics on stable isotopes in precipitation observed in Southern Meghalaya, NE India, Earth Planet. Sci. Lett., 292, 212-220, 2010 .
Chandra, N., Lal, S., Venkataramani, S., Patra, P. K., and Sheel, V.: Temporal variations of atmospheric $\mathrm{CO}_{2}$ and $\mathrm{CO}$ at Ahmedabad in western India, Atmos. Chem. Phys., 16, 6153-6173, https://doi.org/10.5194/acp-16-6153-2016, 2016.

Department of Agriculture \& Cooperation, Ministry of Agriculture (DAC/MA): Agricultural Statistics at a Glance 2014, Directorate of Economics and Statistics, Department of Agriculture and Cooperation (DAC), Ministry of Agriculture (MA), Government of India, OUP, New Delhi, India, ISBN 0-19-945965-7, available at: https://eands.dacnet.nic.in/PDF/ Agricultural-Statistics-At-Glance2014.pdf (last access: 25 May 2019), 2015.

Directorate of Economics and Statistics, Ministry of Agriculture and Farmers Welfare (DES/MAFW): Crop Production Statistics for Selected States, Crops and Range of Year, available at: https://aps.dac.gov.in/APY/Public_Report1.aspx, last access: 31 July 2019.

Dickerson, R. R., Andreae, M. O., Campos, T., Mayol-Bracero, O. L., Neusuess, C., and Streets, D. G.: Analysis of black carbon and carbon monoxide observed over the Indian Ocean: Implications for emissions and photochemistry, J. Geophys. Res.-Atmos., 107, 8017, https://doi.org/10.1029/2001JD000501, 2002.

EC-JRC/PBL: EDGAR v4.3.2 (1970-2012) on March 2016, Emissions Database for Global Atmospheric Research (EDGAR), European Commission, Joint Research Centre (EC-JRC), Netherlands Environmental Assessment Agency (PBL), available at: http://edgar.jrc.ec.europa.eu (last access: 1 September 2021), 2016.

Friedlingstein, P., Jones, M. W., O’Sullivan, M., Andrew, R. M., Hauck, J., Peters, G. P., Peters, W., Pongratz, J., Sitch, S., Le Quéré, C., Bakker, D. C. E., Canadell, J. G., Ciais, P., Jackson, R. B., Anthoni, P., Barbero, L., Bastos, A., Bastrikov, V., Becker, M., Bopp, L., Buitenhuis, E., Chandra, N., Chevallier, F., Chini, L. P., Currie, K. I., Feely, R. A., Gehlen, M., Gilfillan, D., Gkritzalis, T., Goll, D. S., Gruber, N., Gutekunst, S., Harris, I., Haverd, V., Houghton, R. A., Hurtt, G., Ilyina, T., Jain, A. K., Joetzjer, E., Kaplan, J. O., Kato, E., Klein Goldewijk, K., Korsbakken, J. I., Landschützer, P., Lauvset, S. K., Lefèvre, N., Lenton, A., Lienert, S., Lombardozzi, D., Marland, G., McGuire, P. C., Melton, J. R., Metzl, N., Munro, D. R., Nabel, J. E. M. S., Nakaoka, S.-I., Neill, C., Omar, A. M., Ono, T., Peregon, A., Pierrot, D., Poulter, B., Rehder, G., Resplandy, L., Robertson, E., Rödenbeck, C., Séférian, R., Schwinger, J., Smith, N., Tans, P. P., Tian, H., Tilbrook, B., Tubiello, F. N., van der Werf, G. R., Wiltshire, A. J., and Zaehle, S.: Global Carbon Budget 2019, Earth Syst. Sci. Data, 11, 1783-1838, https://doi.org/10.5194/essd-111783-2019, 2019.

Gaihre, Y. K., Singh, U., Islam, S. M., Huda, A., Islam, M. R., Sanabria, J., Satter, M. A., Islam, M. R., Biswas, J. C., Jahiruddin, M., and Jahan, M. S.: Nitrous oxide and nitric oxide emissions and nitrogen use efficiency as affected by nitrogen placement in lowland rice fields, Nutr. Cycl. Agroecosystems, 110, 277-291, 2018.

Ganesan, A. L., Chatterjee, A., Prinn, R. G., Harth, C. M., Salameh, P. K., Manning, A. J., Hall, B. D., Mühle, J., Meredith, L. K., Weiss, R. F., O’Doherty, S., and Young, D.: The variability of methane, nitrous oxide and sulfur hexafluoride in Northeast India, Atmos. Chem. Phys., 13, 10633-10644, https://doi.org/10.5194/acp-13-10633-2013, 2013. 
Garg, A., Kankal, B., and Shukla, P. R.: Methane emissions in India: Sub-regional and sectoral trends, Atmos. Environ., 45, 49224929, 2011.

Garg, A., Shukla, P. R., and Upadhyay, J.: $\mathrm{N}_{2} \mathrm{O}$ emissions of India: an assessment of temporal, regional and sector trends, Clim. Change, 110, 755-782, https://doi.org/10.1007/s10584011-0094-9, 2012.

Geller, L. S., Elkins, J. W., Lobert, J. M., Clarke, A. D., Hurst, D. F., Butler, J. H., and Myers, R. C.: Tropospheric $\mathrm{SF}_{6}$ : observed latitudinal distribution and trends, derived emissions and interhemispheric exchange time, Geophys. Res. Lett., 24, 675-678, 1997.

Gupta, D. K., Bhatia, A., Kumar, A., Das, T. K., Jain, N., Tomer, R., Sandeep, k. M., Fagodiya, R. K., Dubey, R., and Pathak, H.: Mitigation of greenhouse gas emission from rice-wheat system of the Indo-Gangetic Plain: Through tillage, irrigation and fertilizer management, Agric. Ecosyst. Environ., 230, 1-9, 2016.

Guttikunda, S., Begum, B., and Wadud, Z.: Particulate pollution from brick kiln clusters in the Greater Dhaka region, Bangladesh, Air Qual. Atmos. Health, 6, 357-365, https://doi.org/10.1007/s11869-012-0187-2, 2013.

Hong, C. C., Li, T., and Kug, J. S.: Asymmetry of the Indian Ocean dipole. Part I: observational analysis, J. Clim., 21, 4834-4848, 2008.

International Atomic Energy Agency (IAEA): Reference and comparison materials for light isotopes of light elements, Proceedings of a consultants meeting held in Vienna, IAEATECDOC-825, 159, available at: https://www-pub.iaea.org/ MTCD/Publications/PDF/te_825_prn.pdf (last access: 4 October 2020), 1993.

Keeling, C. D.: Rewards and penalties of monitoring the Earth, Annu. Rev. Energ. Environ., 23, 25-82, 1998.

Kim, S., Coplen, T. B., and Horita, J.: Normalization of stable isotope data for carbonate minerals: Implementation of IUPAC guidelines, Geochim. Cosmochim. Acta, 158, 276-289, 2015.

Kumar, A., Sanyal, P., and Agrawal, S.: Spatial distribution of $\delta^{18} \mathrm{O}$ values of water in the Ganga river basin: Insight into the hydrological processes, J. Hydrol., 571, 225-234, 2019.

Kumar, R., Naja, M., Satheesh, S. K., Ojha, N., Joshi, H., Sarangi, T., Pant, P., Dumka, U. C. Hegde, P., and Venkataramani, S.: Influences of the springtime northern Indian biomass burning over the central Himalayas, J. Geophys. Res.-Atmos., 116, D19302, https://doi.org/10.1029/2010JD015509, 2011.

Kumar, R., Naja, M., Pfister, G. G., Barth, M. C., and Brasseur, G. P.: Source attribution of carbon monoxide in India and surrounding regions during wintertime, J. Geophys. Res.-Atmos., 118, 1981-1995, 2013.

Lawrence, M. G. and Lelieveld, J.: Atmospheric pollutant outflow from southern Asia: a review, Atmos. Chem. Phys., 10, 1101711096, https://doi.org/10.5194/acp-10-11017-2010, 2010.

Lin, X., Indira, N. K., Ramonet, M., Delmotte, M., Ciais, P., Bhatt, B. C., Reddy, M. V., Angchuk, D., Balakrishnan, S., Jorphail, S., Dorjai, T., Mahey, T. T., Patnaik, S., Begum, M., Brenninkmeijer, C., Durairaj, S., Kirubagaran, R., Schmidt, M., Swathi, P. S., Vinithkumar, N. V., Yver Kwok, C., and Gaur, V. K.: Longlived atmospheric trace gases measurements in flask samples from three stations in India, Atmos. Chem. Phys., 15, 98199849, https://doi.org/10.5194/acp-15-9819-2015, 2015.
Lohan, S. K., Jat, H. S., Yadav, A. K., Sidhu, H. S., Jat, M. L., Choudhary, M., Peter, J. D., and Sharma, P. C.: Burning issues of paddy residue management in north-west states of India, Renew. Sust. Energ., 81, 693-706, 2018.

Machida, T., Matsueda, H., Sawa, Y., Nakagawa, Y., Hirotani, K., Kondo, N., Goto, K., Nakazawa, T., Ishikawa, K., and Ogawa T.: Worldwide Measurements of Atmospheric $\mathrm{CO}_{2}$ and Other Trace Gas Species Using Commercial Airlines, J. Atmos. Ocean. Technol., 25, 1744-1754, https://doi.org/10.1175/2008JTECHA1082.1, 2008.

Maithel, S., Uma, R., Bond, T., Baum, E., and Thao, V. T. K.: Brick kilns performance assessment, emissions measurements, and a roadmap for cleaner brick production in India, Study report prepared by Green Knowledge Solutions, New Delhi, 2012.

Mukai H.: NIES pure $\mathrm{CO}_{2}$ sample for inter-laboratory comparison of $\mathrm{C}$ and $\mathrm{O}$ isotope ratio analysis especially for atmospheric $\mathrm{CO}_{2}$, proceeding of the 11th WMO/IAEA Meeting of Experts on Carbon Dioxide Concentration and Related Tracer Measurement Techniques, 148, 31, available at: https://library.wmo.int/doc_ num.php?explnum_id=9221 (last access: 16 September 2020), 2001.

Mukai, H.: Inter-Comparison Of Isotope Ratios For $\mathrm{CO}_{2}$ Using Several Reference Materials, proceeding of the 12th WMO/IAEA Meeting of Experts on Carbon Dioxide Concentration and Related Tracers Measurement Techniques, 162, 58-63, available at: https://library.wmo.int/doc_num.php?explnum_id= 9298 (last access: 16 September 2020), 2003.

Naja, M., Bhardwaj, P., Singh, N., Kumar, P., Kumar, R., Ojha, N., Sagar, R., Satheesh, S. K., Moorthy, K. K., and Kotamarthi, V. R.: High-frequency vertical profiling of meteorological parameters using AMF1 facility during RAWEX-GVAX at ARIES, Nainital, Curr. Sci., 111, 132-140, 2016.

NOAA/ESRL: The 6th WMO/IAEA Round Robin Comparison Experiment, available at: http://www.esrl.noaa.gov/gmd/ccgg/ wmorr/wmorr_results.php?rr=rr6\&param $=$ co2\& group=group5, last access: 15 May 2019a.

NOAA/ESRL: ESRL/GMD FTP Data Finder, available at: https: //www.esrl.noaa.gov/gmd/dv/data/, last access: 15 May $2019 \mathrm{~b}$.

NOAA/ESRL: Dipole Mode Index, available at: https://www.esrl. noaa.gov/psd/gcos_wgsp/Timeseries/DMI/, last access: 6 April 2021a.

NOAA/ESRL: Multivariate ENSO Index, available at: https://www. esrl.noaa.gov/psd/enso/mei/, last access: 6 April 2021 b.

Nomura, S., Naja, M., Ahmed, M. K., Mukai, H., Terao, Y., Machida, T., Sasakawa, M., and Patra, P. K.: GHGs mole fraction and carbon isotopic ratio at Nainital, India and Comilla, Bangladesh, available at: https://db.cger.nies.go.jp/portal/geds/ atmosphericAndOceanicMonitoring?lang=eng, last access: 1 September 2021.

Novelli, P. C., Lang, P. M., Masarie, K. A., Hurst, D. F., Myers, R., and Elkins, J. W.: Molecular hydrogen in the troposphere: Global distribution and budget, J. Geophys. Res.-Atmos., 104, 30427-30444, 1999.

Olivier, J. G. J., Van Aardenne, J. A., Dentener, F., Ganzeveld, L., and Peters J. A. H. W.: Recent trends in global greenhouse gas emissions: regional trends and spatial distribution of key sources, in: Non- $\mathrm{CO}_{2}$ Greenhouse Gases (NCGG-4), edited by: Van Amstel, A., 325-330, Millpress, Rotterdam, The Netherlands, 2005. 
Pandey, A. K., Mishra, A. K., Kumar, R., Berwal, S., Devadas, R., Huete, A., and Kumar, K.: CO variability and its association with household cooking fuels consumption over the Indo-Gangetic Plain, Environ. Pollut., 222, 83-93, 2017.

Patra, P. K., Canadell, J. G., Houghton, R. A., Piao, S. L., Oh, N. H., Ciais, P., Manjunath, K. R., Chhabra, A., Wang, T., Bhattacharya, T., Bousquet, P., Hartman, J., Ito, A., Mayorga, E., Niwa, Y., Raymond, P. A., Sarma, V. V. S. S., and Lasco, R..: The carbon budget of South Asia, Biogeosciences, 10, 513-527, 2013.

Price, H., Jaegle, L., Rice, A., Quay, P., Novelli, P. C., and Gammon, R.: Global budget of molecular hydrogen and its deuterium content: Constraints from ground station, cruise, and aircraft observations, J. Geophys. Res.-Atmos., 112, D22108, https://doi.org/10.1029/2006JD008152, 2007.

Raut, N., Sitaula, B. K., and Bajracharya, R. M.: Agricultural intensification in South Asia and its contribution to greenhouse gas emission: A review, Asian Jornal of water, Environ. Pollut., 8, 11-17, 2011.

Roxy, M. K., Ritika, K., Terray, P., Murtugudde, R., Ashok, K., and Goswami, B. N.: Drying of Indian subcontinent by rapid Indian Ocean warming and a weakening land-sea thermal gradient, Nat. Commun., 6, 7423, 2015.

Rozanski, K., Araguás-Araguás, L., and Gonfiantini, R.: Isotopic patterns in modern global precipitation, in: Climate Change in Continental Isotopic Records, Geophys. Monogr. Ser., edited by: Swart, P. K., Lohmann, K. C., Mckenzie, J., and Savin, S., 78, 1-36, AGU, Washington, D. C., USA, https://doi.org/10.1029/GM078p0001, 1993.

Sahai, S., Sharma, C., Singh, D. P., Dixit, C. K., Singh, N., Sharma, P., Singh, K., Bhatt, S., Ghude, S., Gupta, V., Gupta, R. K., Tiwari, M. K., Garg, S. C., Mitra, A. P., and Gupta, R. K.: A study for development of emission factors for trace gases and carbonaceous particulate species from in situ burning of wheat straw in agricultural fields in India, Atmos. Environ., 41, 9173-9186, 2007.

Sahai, S., Sharma, C., Singh, S. K., and Gupta, P. K.: Assessment of trace gases, carbon and nitrogen emissions from field burning of agricultural residues in India, Nutr. Cycl. Agroecosystems, 89, 143-157, https://doi.org/10.1007/s10705-010-9384-2, 2011.

Saji, N. H., Goswami, B. N., Vinayachandran, P. N., and Yamagata, T.: A dipole mode in the tropical Indian Ocean, Nature, 401, 360363, https://doi.org/10.1038/43854, 1999.

Sengupta, S. and Sarkar, A.: Stable isotope evidence of dual (Arabian Sea and Bay of Bengal) vapour sources in monsoonal precipitation over north India, Earth Planet. Sci. Lett., 250, 511-521, 2006.

Sfez, S., De Meester, S., and Dewulf, J.: Co-digestion of rice straw and cow dung to supply cooking fuel and fertilizers in rural India: Impact on human health, resource flows and climate change, Sci. Total Environ., 609, 1600-1615, 2017.

Sharma, N., Nayak, R. K., Dadhwal, V. K., Kant, Y., and Ali, M. M.: Temporal variations of atmospheric $\mathrm{CO}_{2}$ in Dehradun, India during 2009, Air Soil Water Res., 6, 37-45, 2013.

SID/MP.: Statistical Year Book Bangladesh 2018, Statistics and Informatics Division (SID), Ministry of Planning (MP), Government of the people's republic of Bangladesh, Dhaka, Bangladesh, 1-599, 2018.

Sreenivas, G., Mahesh, P., Subin, J., Kanchana, A. L., Rao, P. V. N., and Dadhwal, V. K.: Influence of Meteorology and in- terrelationship with greenhouse gases $\left(\mathrm{CO}_{2}\right.$ and $\left.\mathrm{CH}_{4}\right)$ at a suburban site of India, Atmos. Chem. Phys., 16, 3953-3967, https://doi.org/10.5194/acp-16-3953-2016, 2016.

Streets, D. G., Yarber, K. F., Woo, J.-H., and Carmichael, G. R.: Biomass burning in Asia: Annual and seasonal estimates and atmospheric emissions, Global Biogeochem. Cy., 17, 1099, https://doi.org/10.1029/2003GB002040, 2003.

Swapna, P., Krishnan, R., and Wallace, J. M.: Indian Ocean and monsoon coupled interactions in a warming environment, Clim. Dyn., 42, 2439-2454, 2014.

Tanoue, M., Ichiyanagi, K., Yoshimura, K., Kiguchi, M., Terao, T., and Hayashi, T.: Seasonal variation in isotopic composition and the origin of precipitation over Bangladesh, Prog. Earth Planet. Sci., 5, 77, https://doi.org/10.1186/s40645-018-0231-4, 2018.

Thompson, R. L., Ishijima, K., Saikawa, E., Corazza, M., Karstens, U., Patra, P. K., Bergamaschi, P., Chevallier, F., Dlugokencky, E., Prinn, R. G., Weiss, R. F., O’Doherty, S., Fraser, P. J., Steele, L. P., Krummel, P. B., Vermeulen, A., Tohjima, Y., Jordan, A., Haszpra, L., Steinbacher, M., Van der Laan, S., Aalto, T., Meinhardt, F., Popa, M. E., Moncrieff, J., and Bousquet, P.: TransCom $\mathrm{N}_{2} \mathrm{O}$ model inter-comparison - Part 2: Atmospheric inversion estimates of $\mathrm{N}_{2} \mathrm{O}$ emissions, Atmos. Chem. Phys., 14, 6177-6194, https://doi.org/10.5194/acp-14-6177-2014, 2014.

Thoning, K. W., Tans, P. P., and Komhyr, W. D.: Atmospheric carbon dioxide at Mauna Loa Observatory, 2. Analysis of the NOAA GMCC data, 1974-1985, J. Geophys. Res.-Atmos., 94, 85498565, 1989.

Tiwari, Y. K., Vellore, R. K., Ravi Kumar, K., van der Schoot, M., and Cho, C.-H.: Influence of monsoons on atmospheric $\mathrm{CO}_{2}$ spatial variability and ground-based monitoring over India, Sci. Total Environ., 490, 570-578, https://doi.org/10.1016/j.scitotenv.2014.05.045, 2014.

Umezawa, T., Niwa, Y., Sawa, Y., Machida, T., and Matsueda, H.: Winter crop $\mathrm{CO}_{2}$ uptake inferred from CONTRAIL measurements over Delhi, India, Geophys. Res. Lett., 43, 11859-11866, https://doi.org/10.1002/2016GL070939, 2016.

Venkataraman, C., Habib, G., Kadamba, D., Shrivastava, M., Leon, J. F., Crouzille, B., Boucher, O., and Streets, D. G.: Emissions from open biomass burning in India: Integrating the inventory approach with high-resolution Moderate Resolution Imaging Spectroradiometer (MODIS) active-fire and land cover data, Glob. Biogeochem. Cycles, 20, GB2013, https://doi.org/10.1029/2005GB002547, 2006.

Venkataraman, C., Sagar, A. D., Habib, G., Lam, N., and Smith, K. R.: The Indian national initiative for advanced biomass cookstoves: the benefits of clean combustion, Energy Sustain. Dev., 14, 63-72, 2010.

World Data Centre for Greenhouse Gases (WDCGG): Data search, available at: https://gaw.kishou.go.jp/search/station\#CRI, last access: 2 November 2021.

Yashiro, H., Sudo, K., Yonemura, S., and Takigawa, M.: The impact of soil uptake on the global distribution of molecular hydrogen: chemical transport model simulation, Atmos. Chem. Phys., 11, 6701-6719, https://doi.org/10.5194/acp-11-6701-2011, 2011.

Zeng, J. and Fujinuma, Y.: New web site launched for online air trajectory calculation, EOS, 85, 482-4833, https://doi.org/10.1029/2004EO460004, 2004. 